\title{
Heavy Rainfall Associated with Double Low-Level Jets over Southern China. Part I: Ensemble-Based Analysis
}

\author{
Yu Du AND GUIXING CHEN \\ Center for Monsoon and Environment Research, School of Atmospheric Sciences, and Guangdong Province Key \\ Laboratory for Climate Change and Natural Disaster Studies, Sun Yat-sen University, Guangzhou, China
}

(Manuscript received 20 March 2018, in final form 6 September 2018)

\begin{abstract}
Heavy rainfall occurred at both the inland frontal zone and coastal warm sector in southern China during 10-11 May 2014, which is a typical pattern in the early-summer rainy season. To clarify the key factors controlling the rainfall, we conduct an ensemble-based analysis using the operational global ensemble forecasts from ECMWF. The forecasts of frontal (warm sector) rainfall have a relatively small (large) spread and a small (large) bias of ensemble-mean amount, suggesting an obvious difference in the predictability. It is shown that double low-level jets (LLJs) in the southwesterly moist flow play a significant role in the heavy rainfall over southern China. The inland frontal rainband is closely related to the synoptic-system-related low-level jet (SLLJ) with maximum wind speed at $850-700 \mathrm{hPa}$, especially for its meridional wind component. The more intense cold front is accompanied by the stronger southwesterly SLLJ on the adjacent south side, favoring more precipitation near the front. The warm-sector heavy rainfall, a few hundred kilometers away from the front, is associated with the boundary layer jet (BLJ) at $925 \mathrm{hPa}$. The southerly BLJ occurs over the northern region of the South China Sea and reaches its maximum wind speed in the early morning. The variations of the BLJ are mainly induced by the surface low and related upper-level short-wave trough upstream. The large pressure gradient to the southeast of the surface low can accelerate the BLJ by increasing the geostrophic winds. The diurnal cycle of the low-level winds, seen in the climatology, also contributes in part to the development of the BLJ at night.
\end{abstract}

\section{Introduction}

Heavy rainfall over southern China during the earlysummer rainy season (May-June) often occurs near the quasi-stationary front (hereafter, frontal heavy rainfall) and in the warm sector of a surface baroclinic wave cyclone a few hundred kilometers away from the front (hereafter, warm-sector heavy rainfall), causing large economic and human losses (Huang et al. 1986; Ding 1994; Luo et al. 2017; Chen et al. 2018). Luo (2017) summarized advances in understanding the early-summer heavy rainfall over southern China. These two types of heavy rainfall are different in terms of the mechanisms of their initiation, formation, and maintenance. The warm-sector heavy rainfall is not well understood, compared to frontal heavy rainfall (Luo et al. 2017; Luo 2017). For the frontal heavy rainfall, the front between the warm, moist, southerly winds and cold, dry, northerly winds provides the boundary to provide upward motion within a deep moist unstable layer (Zhao et al. 2007).

Corresponding author: Yu Du, duyu7@mail.sysu.edu.cn
A southwesterly low-level jet (LLJ) related to the synoptic or subsynoptic front transports warm and moist air to the front and destabilizes the environment, which favors the development of heavy rainfall near the front (Chen and Yu 1988; Tao and Chen 1987; Akiyama 1973; Chen et al. 1994; Trier et al. 1990). However, an obvious synoptic-scale boundary, such as a front, is absent for the warm-sector heavy rainfall; thus, the forecast of their location and timing is still very difficult.

Previous studies documented that warm-sector heavy rainfall may be associated with low-level jets in the boundary layer (Luo et al. 2017), cold pools (Wang et al. 2014), mesoscale convective vortices (Schumacher and Johnson 2008), and terrain effects (Wang et al. 2014; Tu et al. 2014). Wu and Luo (2016) conducted analysis of the data from high-resolution surface observations, soundings, and radars for the case on 20 May 2015. They found that the LLJ, local terrain, and cold pools are key factors for the initialization and maintenance of convection at the coastal area far away from the front. Luo et al. (2017) studied another warm-sector heavy rainfall on 23 May 2014 and suggested similar key factors. 
Idealized numerical experiments also suggest that the low-level wind speed greatly influences the intensity and diurnal variations of rainfall over the southern China coast during the early-summer season (Chen et al. 2017). All these previous studies emphasized the important role of the LLJ in the convective-triggering and organizing mechanisms.

The LLJs over southern China during the early summer could be classified into two types (Chen et al. 1994; $\mathrm{Du}$ et al. 2012, 2014). The first type is the synopticsystem-related low-level jet (SLLJ), which occurs in the low levels of free troposphere (900-600-hPa layer) in association with synoptic-scale weather systems. The second type is the boundary layer jet (BLJ), which occurs in the boundary layer with obvious vertical shear and a diurnal cycle with a maximum horizontal wind speed at night. The BLJ can be influenced by both boundary processes and large-scale circulation or weather systems. These two types of LLJs exhibit different formation mechanisms and characteristics (Du et al. 2014). Inertial oscillation (Blackadar mechanism; Blackadar 1957) and thermal contrast near the terrain or coastal areas (Holton mechanism; Holton 1967) are considered as the two most popular theories for the occurrence of nocturnal BLJs. Some studies suggested the importance of combining both theories (Jiang et al. 2007; Du and Rotunno 2014; Shapiro et al. 2016) in determining the detailed features of the BLJs. On the other hand, the formation mechanisms of SLLJs include isallobaric forcing (Uccellini and Johnson 1979; Uccellini 1980), low-level baroclinicity by extratropical cyclones (Djurić and Damiani 1980; Newton 1967), and diabatic effects (Uccellini et al. 1987).

Previous studies suggest that both BLJs and SLLJs are closely related to heavy rainfall (Stensrud 1996), but few studies compare their effects on heavy rainfall. Nocturnal U.S. Great Plains LLJs, classified as BLJs, are responsible for nocturnal heavy rainfall (Means 1952; Pitchford and London 1962; Hering and Borden 1962). The supergeostrophic Great Plains BLJ at night may enhance vertical shear and provide the moisture that increases moist static energy for convection (Trier et al. 2006) and promote convection at the exit region of the BLJ by enhancing the frontogenesis (Augustine and Caracena 1994). The MCS precipitation forecast skill significantly correlated with the forecast accuracy of the U.S. Great Plains LLJ wind direction (Squitieri and Gallus 2016). SLLJs are closely related to heavy rainfall along the stationary or cold front troughs embedded in mesoscale convective systems (Matsumoto et al. 1971; Akiyama 1973). SLLJs form to the south of heavy rainfall as a part of the secondary circulation driven by convective latent heating (Chen and Yu 1988; Chen 1982; Chou et al. 1990). Huang and Luo (2017), using the ensemble sensitivity, found that the transport of warm moist air into South China by the low-level southwesterly flow is a key synoptic factor on rainfall over southern China. Over southern China, both BLJ and SLLJ exist and show different characteristics and mechanisms (Du et al. 2014). However, the differences between the effects of the BLJ and the SLLJ on heavy rainfall are not well understood.

In this study, we attempt to investigate the effects of both BLJs and SLLJs on the frontal and warm-sector heavy rainfall over southern China. In Part I, we use European Centre for Medium-Range Weather Forecasts (ECMWF) ensemble forecasts to examine the key factors (with emphasis on LLJs) for regulating the frontal and warm-sector heavy rainfall. In Du and Chen (2018, manuscript submitted to Mon. Wea. Rev., hereafter Part II), we further conduct high-resolution simulations to explore the impacts of double LLJs on convective initiation with emphasis on the warm-sector heavy rainfall. Ensemble-based analysis is a new efficient tool to gain quantitative insights and determine the most important factors into the dynamics of weather systems, which are estimated from ensemble forecasts (Hakim and Torn 2008; Torn 2010). Many studies used similar techniques to explore the genesis and development of mesoscale convective vortices (MCVs) and tropical cyclones (Sippel and Zhang 2008, 2010; Schumacher 2011; Lynch and Schumacher 2014) and torrential rainfall (Huang and Luo 2017; Zhang and Meng 2018). Part I of the present study uses archived operational global ensemble forecasts from the ECMWF to diagnose the dynamics of a typical event of heavy rainfalls over southern China and to access the forecast uncertainty. The data and methods used in this study are described in detail in section 2. The overview of the heavy rainfall event is provided in section 3 . Section 4 presents the results of ensemble-based and composite analyses and further reveals the effect of the BLJ and SLLJ on heavy rainfall. The results are summarized in section 5 .

\section{Data and method}

To present the distribution of hourly rainfall, Climate Prediction Center morphing technique (CMORPH) rainfall data (Joyce et al. 2004) with a high spatial $(8 \mathrm{~km})$ and temporal $(30 \mathrm{~min})$ resolution and dense rain gauge observations are utilized in this study. The CMORPH rainfall is estimated from both low-orbit satellite microwave observation and geostationary satellite IR data. CMORPH has been widely used in previous studies of heavy rainfall (Chen et al. 2018). There are 4633 dense rain gauges from routine surface stations and automatic 

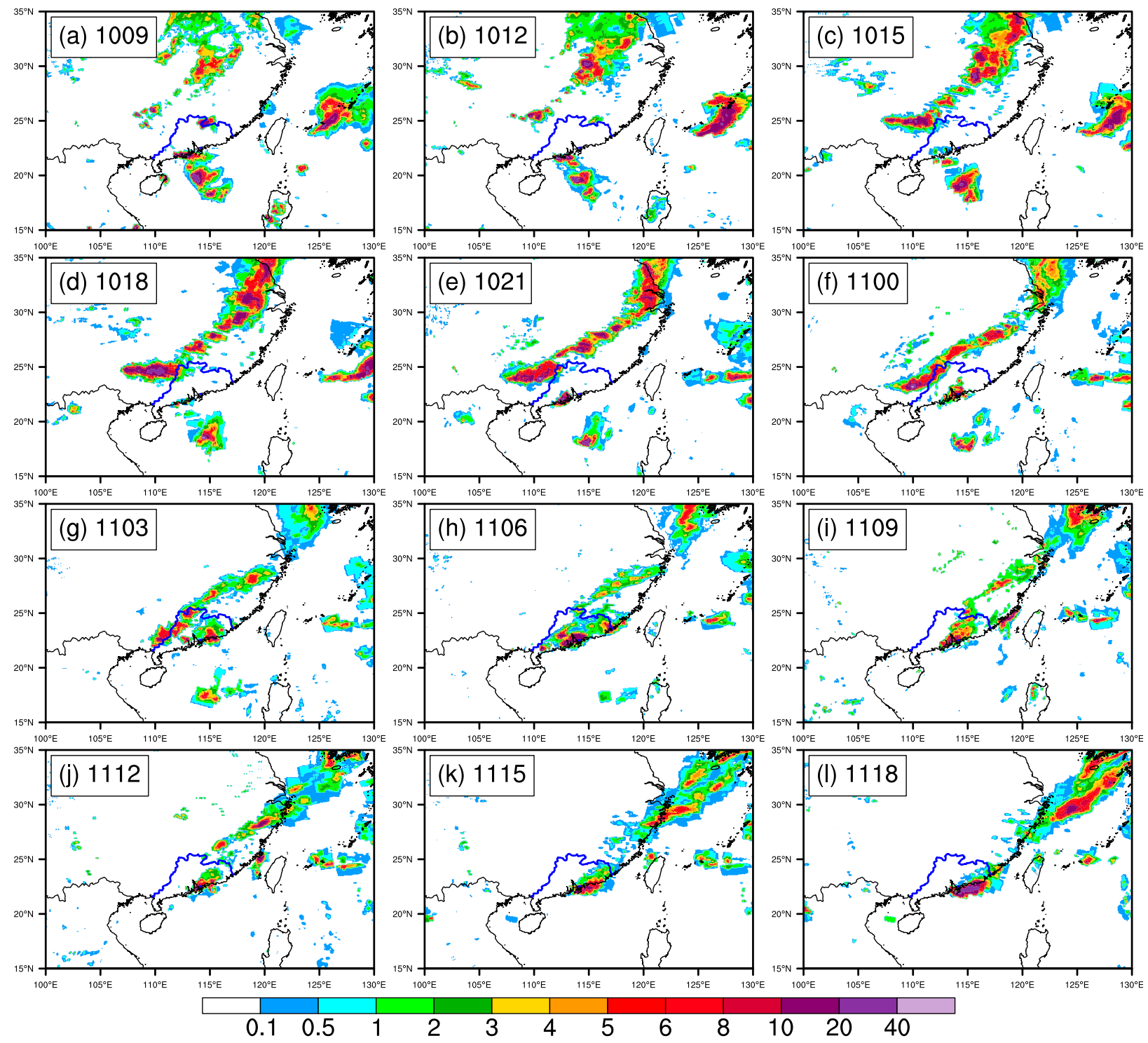

FIG. 1. Distribution of hourly precipitation (mm) from (a) 0900 UTC 10 May to (l) 1800 UTC 11 May based on the CMORPH data. Guangdong Province is indicated by the blue line.

weather stations (AWSs) in Guangdong (indicated by the blue outline in Fig. 1), Guangxi, and Fujian Provinces. Compared with rain gauge observations over land, CMOPRH covers rainfall over the ocean and thus supplements rain gauge observations.

Following the work of Schumacher (2011) and Lynch and Schumacher (2014), the ensemble forecasts with $50-\mathrm{km}$ horizontal resolution from the ECMWF Ensemble Prediction System (Buizza et al. 2007) are used in this study. The original resolution of the ECMWF model is $30-\mathrm{km}$ horizontal grid spacing and 62 vertical levels, which could resolve low-level jets and mesoscale systems with a spatial scale of larger than $150 \mathrm{~km}$. Considering the limitation of model resolution, we mainly focus on the general features of the rainfall process rather than the detailed features of rainfall systems through accessing practical forecast capability of 6-h accumulated rainfall in the ECMWF ensemble forecasts. Huang and Luo (2017) evaluated the predictable capability of global ensemble forecasts from ECMWF, U.S. National Centers for Environmental Prediction (NCEP), Japan Meteorological Agency (JMA), Korea Meteorological Administration, and China Meteorological Administration (CMA) for presummer rainy season rainfall over southern China and found that ECMWF is the most skillful. To increase the number of ensemble members, we employ 150 forecast members with three different initialization times for an ensemble-based 
analysis (50 members for each step; Zhang and Meng 2018). Forecasts for all 150 members were obtained from the TIGGE archive (http://tigge-portal.ecmwf.int). To identify the key factors and understand the behavior within the ECMWF ensemble members, we calculate linear correlations between area-averaged precipitation with several atmospheric variables at each grid point. The correlations with magnitudes greater than 0.16 are statistically different from zero at the $95 \%$ confidence level using a two-tailed significance test. Composites of good members and bad members are constructed to further illustrate the effects of the key factors. The definition of good members and bad members is introduced in section $4 b$.

NCEP Final (FNL) Operational Global Analysis data are used as the analysis of circulation background in this case. ERA-Interim is also checked and shows similar features. The analysis of FNL is shown in section 3 as an observation, considering it is a data source different from ECMWF ensemble forecasts.

\section{Overview of the heavy rainfall event}

On 10-11 May 2014, heavy rainfall of more than $200 \mathrm{~mm} \mathrm{day}^{-1}$ occurred in the coastal area of southern China (Luo et al. 2017). This heavy rainfall event includes inland frontal heavy rainfall and coastal warmsector heavy rainfall, which is a typical type over southern China ( $40 \%$ of heavy rainfall cases; Chen et al. 2018; Ding et al. 2008). Chen et al. (2018) identified two rainfall modes over southern China in its climatology: 1) morning rainfall at coasts that is related to the monsoon and coastal terrain and 2) nocturnal inland rainfall that is associated with migrating rain systems.

Figure 1 shows the distribution of hourly amount of precipitation from CMORPH during 0900 UTC 10 May-1800 UTC 11 May $2014($ LST $=$ UTC +8$)$. At 1500-1800 UTC 10 May (Figs. 1c,d), a narrow band of heavy rainfall extending from southwest to northeast was generated by the cold front. The rainband migrated southeastward from 1500 UTC 10 May to 0300 UTC 11 May (Figs. 1c-g) and affected Guangdong during 0000-0300 UTC 11 May. The maximum rainfall exceeds $40 \mathrm{~mm} \mathrm{~h}^{-1}$ within the inland rainband. In addition to the inland rainband, coastal heavy rainfall occurred in the present event. At 0900 UTC 10 May (Fig. 1a), locally heavy rainfall occurred near the coast of Guangdong Province (indicated by the blue outline), but it quickly weakened during 1200-1800 UTC 10 May 2014. Coastal convection redeveloped at 1800-2100 UTC (Figs. 1d,e), and its associated rainfall was enhanced again in the warm sector far from the cold front (Figs. 1e,f). The newly generated coastal convection moved eastward slowly along the coastline (Figs. 1e-g) and finally merged with the southward-moving frontal rainband (Figs. 1h-1). In the coastal zone, the maximum rain rate also exceeds $40 \mathrm{~mm} \mathrm{~h}^{-1}$.

As shown in Figs. 2a-c, a northeast-southwestoriented shear line at $850 \mathrm{hPa}$ with large gradient zones of equivalent potential temperature approached from the north and collocated with the inland rainband in Fig. 1. Guangdong is situated a few hundred kilometers to the south of the low-level shear line, which is controlled by warm southwesterly winds at $850 \mathrm{hPa}$. The southwesterly $850-\mathrm{hPa}$ winds exceeding $12 \mathrm{~m} \mathrm{~s}^{-1}$ occurred to the south of the cold front, indicating a strong SLLJ related to the front. With the southward-moving shear line, the trough at $500 \mathrm{hPa}$ located north of the shear line became deeper and moved eastward, and the precipitable water increased near the south coast of China. A low-level vortex at $925 \mathrm{hPa}$ over southwestern China was accompanied by a strong southerly wind associated with a BLJ over the northern region of the South China Sea (SCS; Figs. 2d-f). The BLJ was strongest at 0000 UTC 11 May and exceeded $16 \mathrm{~m} \mathrm{~s}^{-1}$. From surface analysis (Figs. 2g-i), a synoptic-scale cold front existed to the north of Guangdong, and the surface low was located over southwestern China.

Horizontal analysis implies that double LLJs might occur over southern China. The vertical cross section of winds along the black line in Fig. $2 \mathrm{~b}$ was plotted from FNL data (Fig. 3a) to verify it. It clearly shows that the BLJ (SLLJ) is over the ocean (land). The vertical sounding profile at Yangjiang (indicated by a black cross in Fig. 2h) near the coast further verifies the double LLJs (Fig. 3b).

In this study, we will focus on the stage (0000-0600 UTC 11 May) when both the inland frontal and coastal warmsector rainfall existed in Guangdong. Figure 4a presents the horizontal distribution of accumulated precipitation during this 6 -h period from CMORPH. There are distinct separate rainfall maxima over Guangdong Province: one is the inland frontal heavy rainfall, indicated by a purple box (hereafter the inland region), and the other is the coastal warm-sector heavy rainfall, indicated by a black box (hereafter the coastal region). The maximum rainfall amount in both the inland and coastal regions exceeds $50 \mathrm{~mm}$ in $6 \mathrm{~h}$. The rainfall from dense surface observations shows similar double rainbands during the same period (Fig. 4b). The maximum rainfall amount from surface observations is higher than rainfall estimated from CMORPH. The number of stations where rainfall amount exceeds $50 \mathrm{~mm}$ in $6 \mathrm{~h}$ is 184 (74) in the coastal (inland) rainband. The dynamical mechanisms of these two rainbands will be explored with ensemblebased analyses in section 4 . 
(a) 1800 UTC 10 May

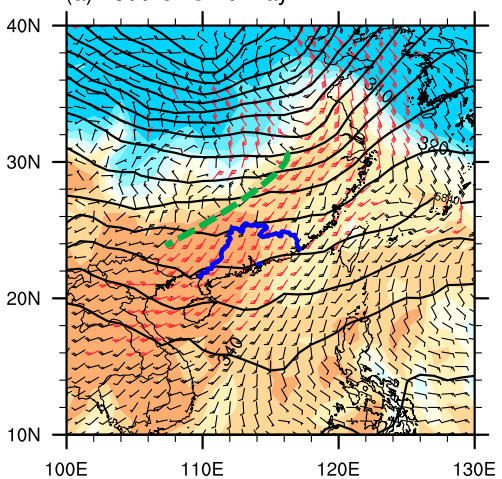

(b) 0000 UTC 11 May

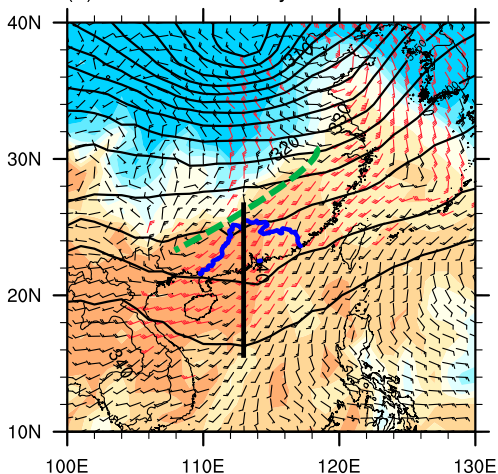

(c) 0600 UTC 11 May

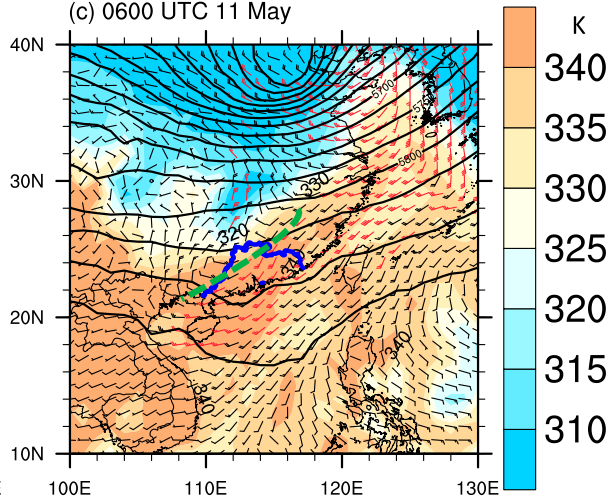

(d) 1800 UTC 10 May

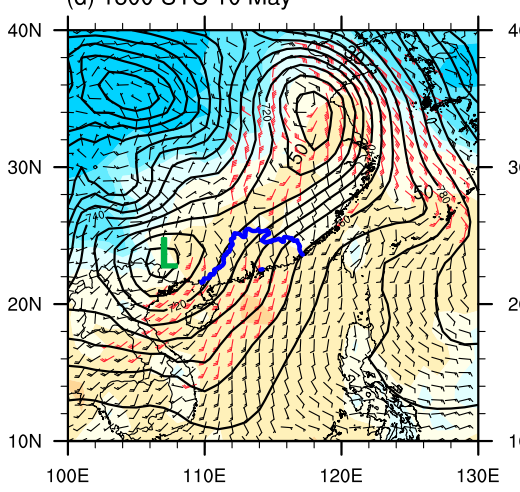

(e) 0000 UTC 11 May

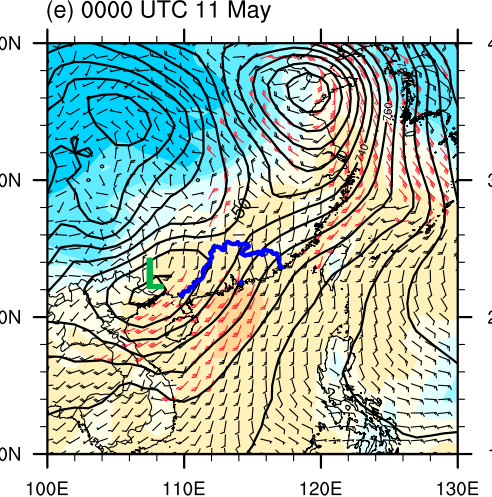

(f) 0600 UTC 11 May

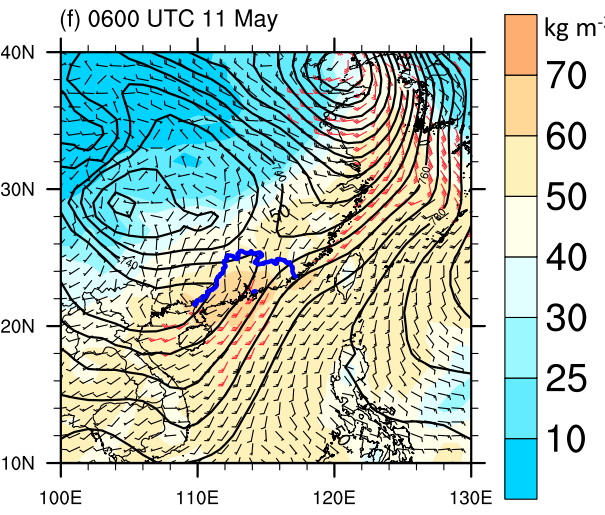

$\mathrm{kg} \mathrm{m}$

60

(g) 1800 UTC 10 May

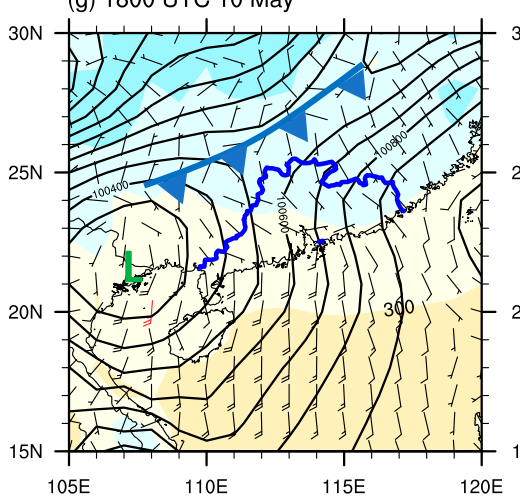

(h) 0000 UTC 11 May

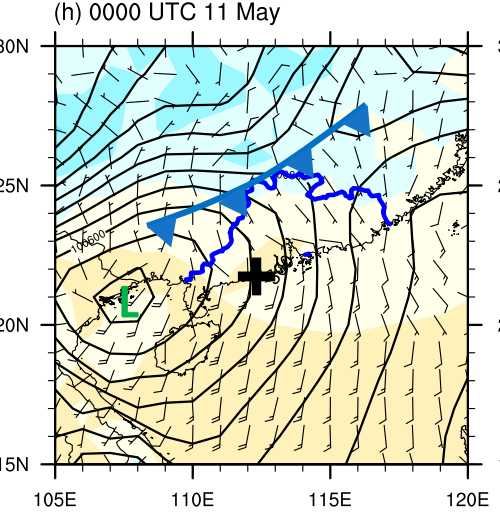

(i) 0600 UTC 11 May

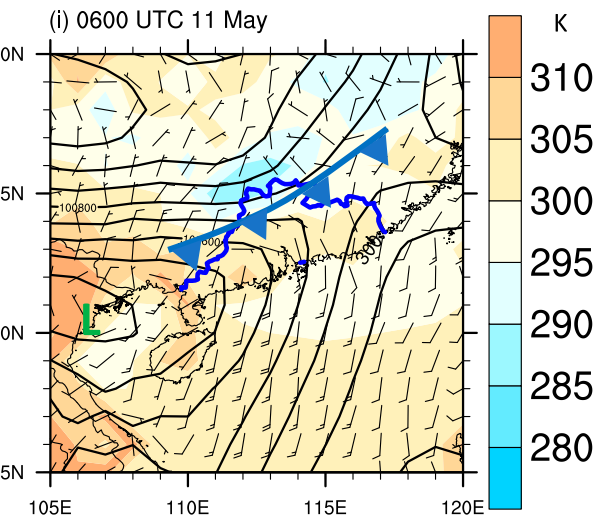

FIG. 2. NCEP FNL Operational Global Analysis data at (a),(d),(g) 1800 UTC 10 May and (b),(e),(h) 0000 and (c),(f),(i) 0600 UTC 11 May 2014 showing (a)-(c) the geopotential height at $500 \mathrm{hPa}$ (black solid contoured at intervals 25 gpm) and the equivalent potential temperature at $850 \mathrm{hPa}\left(\mathrm{K}\right.$; shaded), superimposed with horizontal wind barb at $850 \mathrm{hPa}$ (red above $12 \mathrm{~m} \mathrm{~s}^{-1}$ ); and (d)-(f) the geopotential height at $925 \mathrm{hPa}$ (black solid contoured at intervals $10 \mathrm{gpm})$ and precipitable water $\left(\mathrm{kg} \mathrm{m}^{-2}\right.$; shaded), superimposed with horizontal wind barb at $925 \mathrm{hPa}$. (g)-(i) Sea level pressure (black solid contoured at intervals of $1 \mathrm{hPa}$ ) and surface temperature (K, shaded), superimposed with horizontal surface wind barbs. The green dashed line indicates the wind shear line at $850 \mathrm{hPa}$; the blue lines indicate the surface front, and the green "L" indicates low pressure. Guangdong Province is indicated by blue curves.

\section{Results}

\section{a. Ensemble forecasts}

Figure $4 \mathrm{c}$ shows the ensemble mean of rainfall from the 150 ECMWF ensemble forecasts $(150$ members from forecasts initiated at 1200 UTC 9 May, 0000 UTC
10 May, and 1200 UTC 10 May, with 50 members for each step). It is shown that the ensemble mean can generally capture the inland frontal rainband, but it greatly underestimates the rainfall amount in the coastal region. Each forecast member was checked (not shown) and compared to observations. Some forecasts can capture 


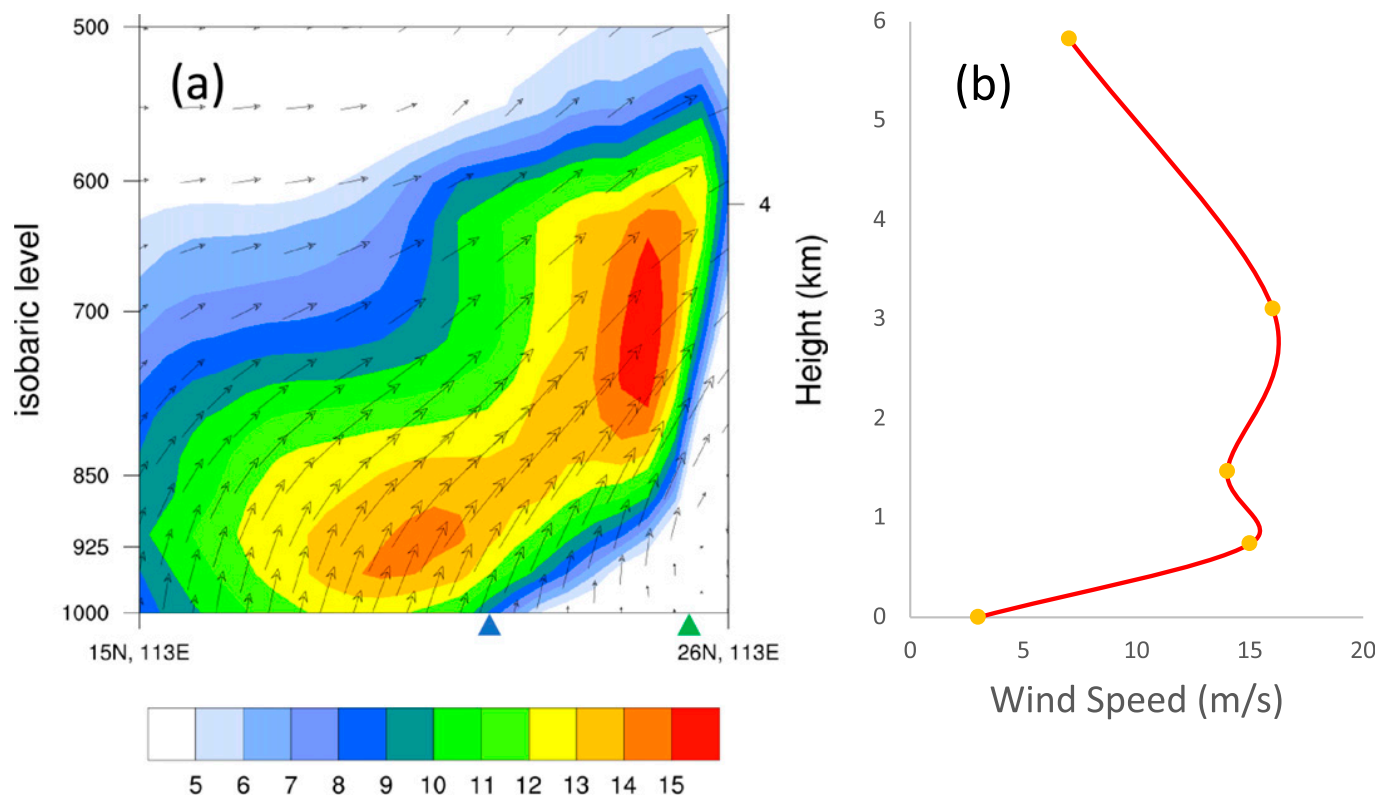

FIG. 3. (a) Vertical cross section of meridional wind speed (shading; $\mathrm{m} \mathrm{s}^{-1}$ ) and horizontal wind vectors (vectors going up means toward the north) along the black line in Fig. 2b at 0000 UTC 11 May 2014. Blue triangle indicates the location of the coast, whereas green triangle indicates the location of the front. (b) Vertical profile of wind speeds at Yangjiang sounding station (black cross in Fig. 2h) at 0000 UTC 11 May 2014.

the two rainbands over Guangdong, but some cannot. In general, the ensemble forecasts have a large spread in the rainfall forecasts over both the inland and coastal regions (Fig. 5). The large spread of ensemble forecasts provides a way, using ensemble-based analysis, to investigate which essential synoptic and mesoscale factors lead to their differences. The spread of coastal rainfall forecasts (RMSE = $4.0)$ is larger than that of inland rainfall ( $\mathrm{RMSE}=3.3$ ). The ensemble mean of the inland rainfall $(12.8 \mathrm{~mm})$ is very close to the observations from CMORPH $(12.9 \mathrm{~mm})$, but the ensemble mean of the coastal rainfall $(10.9 \mathrm{~mm})$ substantially underestimates the observations $(15 \mathrm{~mm})$. Thus, the predictability of the coastal warm-sector rainfall is lower than that of the inland frontal rainfall.

\section{b. The effect of LLJs on the heavy rainfall}

To explore the dynamical processes for the inland frontal rainfall and the coastal warm-sector rainfall, two dependent, area-averaged variables were used in this study: the forecast accumulated precipitation during 0000-0600 UTC 11 May averaged over the inland region (purple box in Fig. 4a; hereafter $P_{I}$ ) and the coastal region (black box in Fig. 4a; hereafter $P_{C}$ ). The linear correlations between atmospheric variables at 0000 UTC 11 May with the two variables $\left(P_{I}\right.$ and $\left.P_{C}\right)$ are analyzed. Figures 6 and 7 present the linear correlation of forecast meridional and zonal winds in ensemble members with $P_{I}$ and $P_{C}$, respectively.
For the inland region, there are obvious positive correlations between $P_{I}$ and the meridional winds at all display levels $(925,850$, and $700 \mathrm{hPa})$ to the south of the inland region (around $22^{\circ} \mathrm{N}, 113^{\circ} \mathrm{E}$; Figs. $6 \mathrm{a}-\mathrm{c}$ ). The positive correlation area occurs almost completely over the land and at all low-to-midlevels, with the maximum around 0.6 . At $850 \mathrm{hPa}$, a negative correlation area also exists to the northwest of the inland region (centered at $\sim 26^{\circ} \mathrm{N}, 110^{\circ} \mathrm{E}$; Fig. $6 \mathrm{~b}$ ). The correlation pattern suggests that rainfall in the inland region is sensitive to the lowto-midlevel southerly winds to the south of the inland region as well as to the northerly winds at $850 \mathrm{hPa}$ to the northwest of the inland region. Moreover, the zonal wind at $700 \mathrm{hPa}$ is correlated with $P_{I}$ to the west of the inland region (Fig. 7c). The correlations between $P_{I}$ and full winds (not shown) also indicate a significant positive correlation at $925-700 \mathrm{hPa}$ to the south of or near the inland region. The low-to-midlevel southwesterly winds correspond to the SLLJ in a deep layer of the low troposphere associated with the cold front. A stronger SLLJ on the adjacent south side of the cold front produces more rainfall near the front. The results are consistent with previous studies of the effect of the SLLJ on frontal heavy rainfall (Matsumoto et al. 1971; Akiyama 1973; Chen and Yu 1988). The results in the present study reveal that the southerly component within the southwesterly SLLJ is more important for the rainfall near the front. 

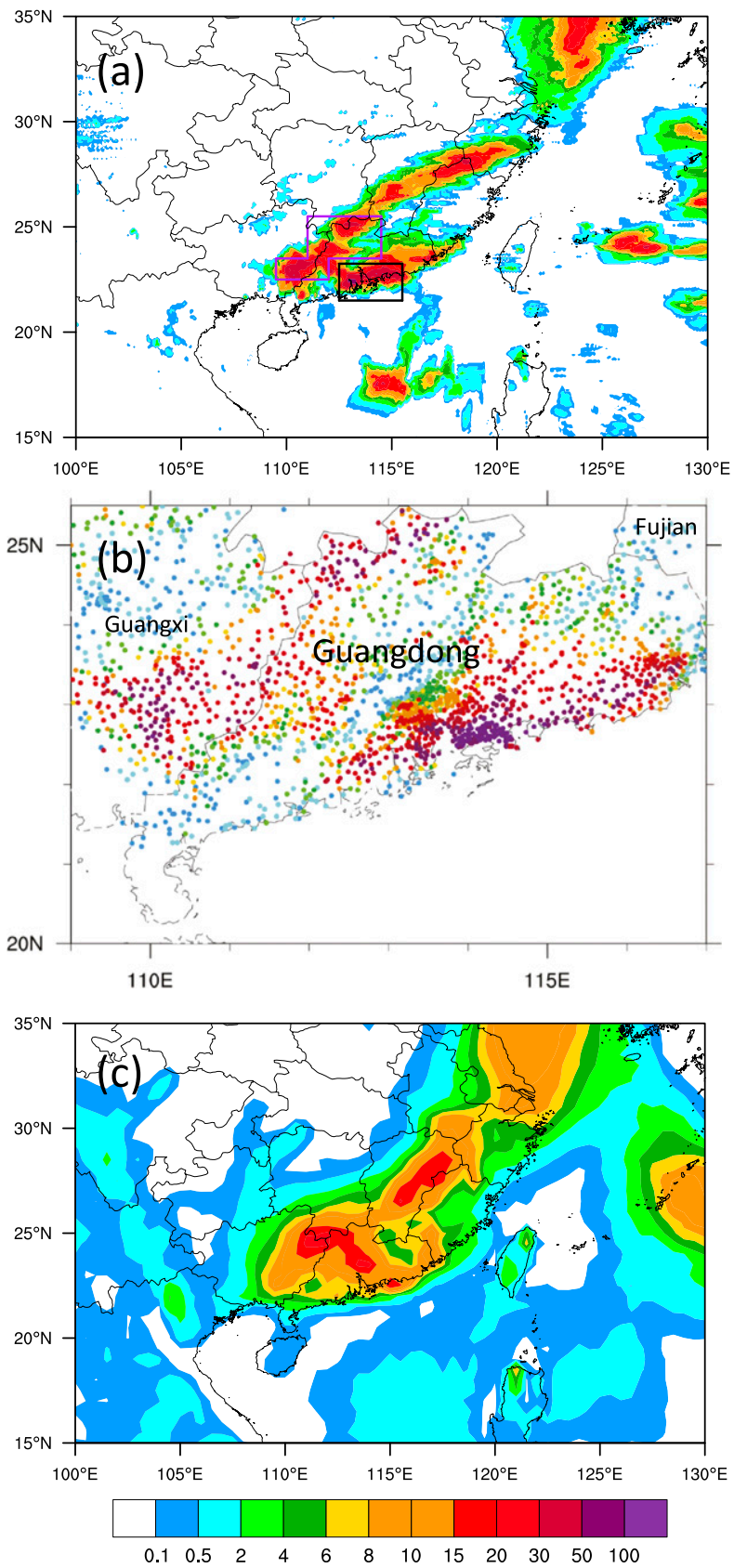

FIG. 4. Distribution of accumulated precipitation $(\mathrm{mm})$ during 0000-0600 UTC 11 May from (a) the CMORPH data, (b) surface observations, and (c) the ECMWF ensemble-mean forecasting initialized at 0000 UTC 9 May. The purple box indicates the inland region, whereas the black box indicates the coastal region.

As for the coastal region, positive correlations between $P_{C}$ and meridional winds at the 925 - and $850-\mathrm{hPa}$ levels are also found to the south of the coastal region (centered at $\sim 20^{\circ} \mathrm{N}, 114^{\circ} \mathrm{E}$; Figs. $6 \mathrm{~d}, \mathrm{e}$ ). However, the 925 -hPa meridional wind correlations with $P_{C}$ (max: $0.57)$ are much greater than the $850-\mathrm{hPa}$ meridional

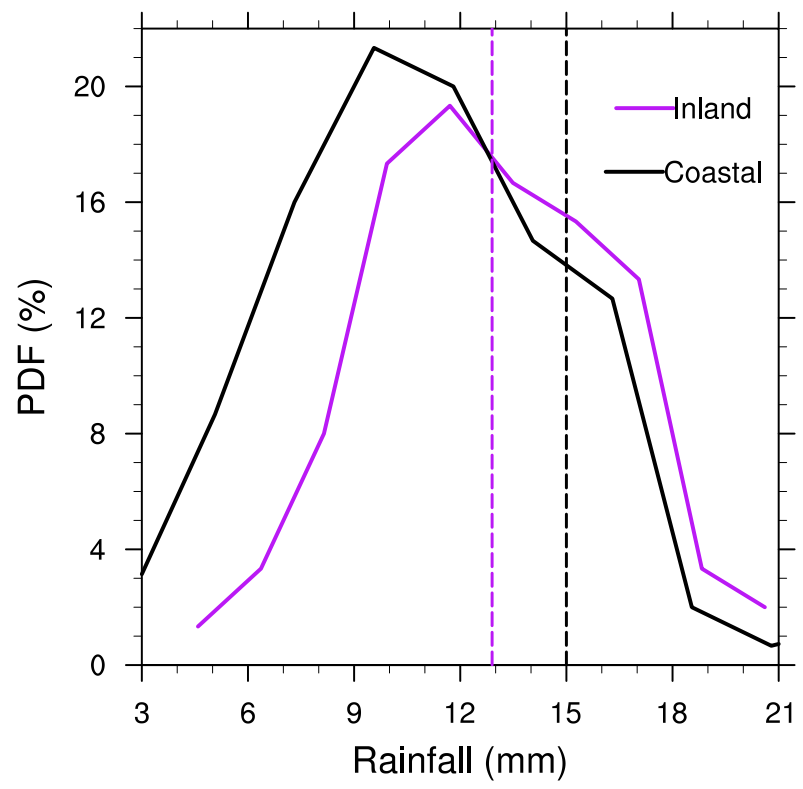

FIG. 5. Probability distribution function of accumulated precipitation during 0000-0600 UTC 11 May averaged over the inland region (purple line) and the coastal region (black line) from the ECMWF ensemble-mean forecasting initialized at 0000 UTC 9 May. The dashed lines indicate the observations.

wind correlations (max: 0.41; Figs. 6d,e). The correlations of meridional winds at $700 \mathrm{hPa}$ with $P_{C}$ are even negative over the same area (Fig. 6e). These correlations suggest that stronger meridional winds in the boundary layer are associated with greater precipitation in the coastal region. Unlike the inland rainfall, the sensitive area for the coastal rainfall is mostly located over the ocean (northern region of the SCS) and is confined within the boundary layer. In Figs. $7 \mathrm{~d}-\mathrm{f}$, the negative zonal wind correlations with $P_{C}$ exist to the east of the coastal region, indicating that the low-level winds confluent to the coastal region favor the coastal rainfall. The positive correlation of meridional winds to the south of the coastal region and negative correlation of zonal winds to the east of the coastal region lead to the positive correlation of convergence $(-\partial v / \partial y-\partial u / \partial x)$ in the coastal region. Furthermore, the southerly winds in the boundary layer represent BLJs over the northern region of the SCS. These results are consistent with previous studies showing that the BLJ plays a key role in the initiation and development of convection near the south coast of China (Luo et al. 2017; Wu and Luo 2016). The interaction between the BLJ and terrain near the southern coast of China is responsible for rainfall near the coast (Chen et al. 2017). The results in the present study reveal that the degree of divergence at the exit region of the BLJ is also important for the coastal rainfall, in addition to the intensity of the BLJ. 

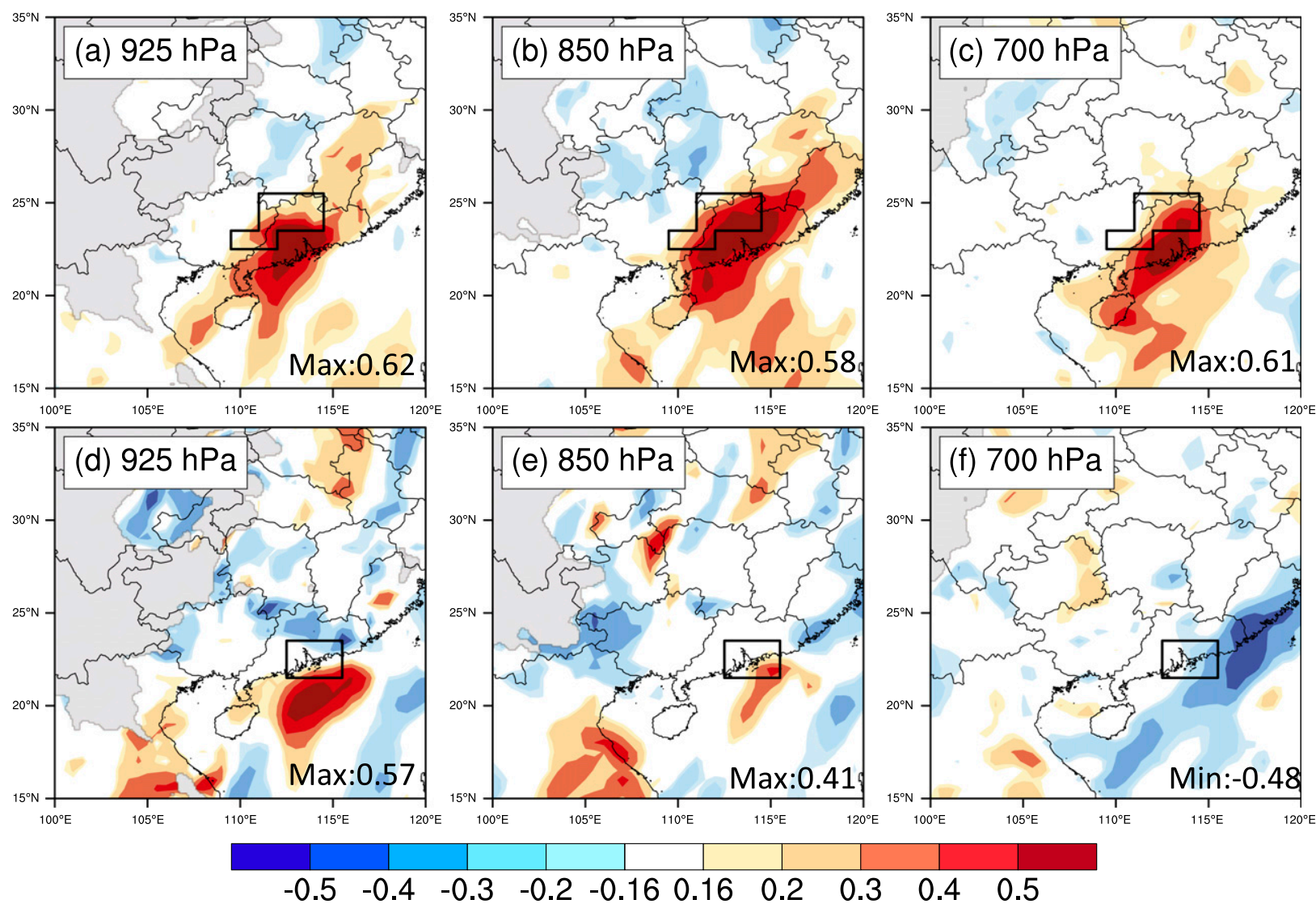

FIG. 6. Correlation of meridional wind at (a),(d) 925, (b),(e) 850, and (c),(f) $700 \mathrm{hPa}$ at 0000 UTC 11 May with area-averaged precipitation during 0000-0600 UTC 11 May over (a)-(c) the north region and (d)-(f) the south region. Gray shading indicates terrain.

To explicitly present the correlations in a physical perspective, composites of good members and bad members were constructed. Considering that most of the coastal rainfall forecasts are underestimated, whereas the inland rainfall forecasts are better in terms of ensemble mean and spread (Figs. 4, 5), we define the good members as the 30 members with the highest values of $P_{C}$ and the bad members as the 30 members with the lowest values of $P_{C}$. Figures $8 \mathrm{a}$ and $8 \mathrm{~b}$ show the averaged rainfall for the good and bad members, respectively. As expected, the rainfall composites of good members indeed capture the observed double rainbands, though their intensities and locations differ somewhat from the observations (Figs. 8a, 4a). In the bad members, the frontal rainfall can roughly be reproduced, but the coastal rainband is much weaker. Figure 9 presents the comparison of good members and bad members in meridional wind $V$ at low levels. The core of 925-hPa $V$ averaged from good members is $\sim 17 \mathrm{~m} \mathrm{~s}^{-1}$ (located to the south of the coastal region, around $20.5^{\circ} \mathrm{N}, 112^{\circ} \mathrm{E}$ ), which is much greater than that of bad members $\left(\sim 14 \mathrm{~m} \mathrm{~s}^{-1}\right)$. The differences of meridional wind at 850 and $700 \mathrm{hPa}$ between good members and bad members are relatively small. The core of 925-hPa wind represents the low-level jets in the boundary layer over the northern region of the SCS. The differences in the wind speed $\left(3 \mathrm{~m} \mathrm{~s}^{-1}\right)$ and the direction of the BLJs in good members and bad members lead to big differences in convergence $\left(\sim 1.2 \times 10^{-5} \mathrm{~s}^{-1}\right)$ in the $P_{C}$ region $\left(-1.6 \times 10^{-5} \mathrm{~s}^{-1}\right.$ in good members and $-0.4 \times$ $10^{-5} \mathrm{~s}^{-1}$ in bad members; not shown). Therefore, the BLJ over the northern region of the SCS is indeed a significant factor in the heavy rainfall over the coastal region.

We also calculated the correlation between $P_{C}$ and $P_{I}$ with winds at 0600 UTC 11 May (not shown). There was obvious strong positive correlation between $u$ and $v$ with $P_{I}$, (located to the southeast of $P_{I}$ ). Since the scale of the SLLJ is synoptic, the correlation can be sustained. However, the correlations between $u$ and $v$ at 0600 UTC 11 May with $P_{C}$ are not as significant as winds at 0000 UTC, which might be related to the diurnal cycle of BLJ with maximum at night or early morning.

\section{c. Other factors on the heavy rainfalls}

SLLJ and BLJ not only exhibit different characteristics and formation mechanisms that have been documented 

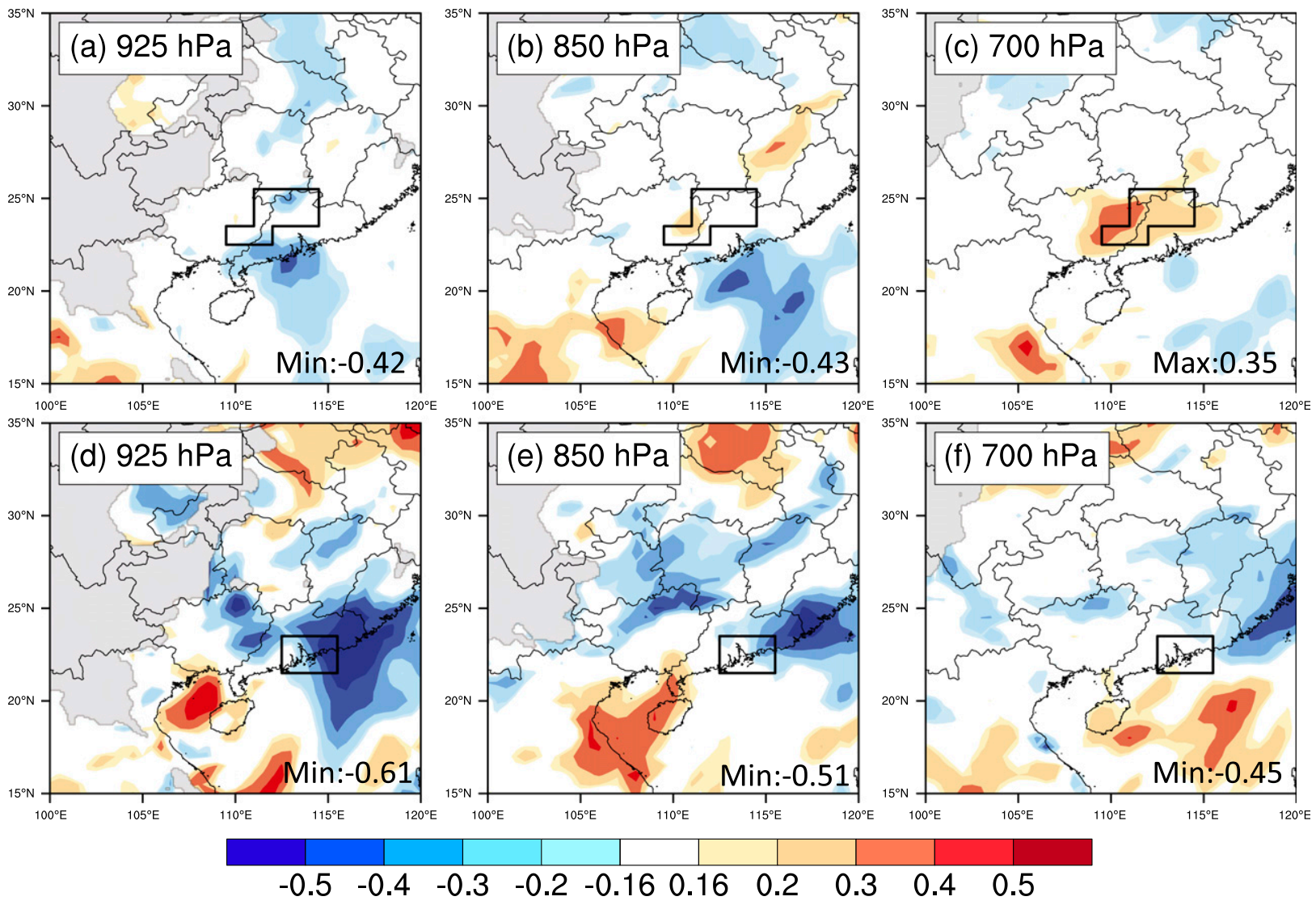

$\begin{array}{llllllllll}-0.5 & -0.4 & -0.3 & -0.2 & -0.16 & 0.16 & 0.2 & 0.3 & 0.4 & 0.5\end{array}$

FIG. 7. As in Fig. 6, but for zonal wind.

in the previous studies (Du et al. 2012, 2014), but also are related to the frontal heavy rainfall and warm-sector heavy rainfall over southern China in the present case, respectively, as shown in the previous subsection. In this subsection, we will further examine other factors that might relate the LLJ (e.g., pressure and temperature) to the heavy rainfall.

Figure 10 shows the correlations among the 500-, 850-, and 925-hPa geopotential heights and the area-averaged rainfall for the inland region and the coastal region $\left(P_{I}\right.$ and $\left.P_{C}\right)$. For rainfall in the inland region $\left(P_{I}\right)$, the large area with negative correlation of geopotential height at low levels $(850$ and $700 \mathrm{hPa})$ is located near the front (Figs. 10b,c), which suggests that the low pressure anomaly (indicating more intense horizontal wind shear) at low levels near the front favors more rainfall in the inland region. We have checked out locations of shear line for all members and found that their differences are small (not shown). In addition, there are negative correlations between the 500 -hPa geopotential height and $P_{C}$ in the western area upstream of the coastal region (Fig. 10d), whereas the negative correlation centers at low levels $(850$ and $925 \mathrm{hPa})$ are located to the southwest of the coastal region (Figs. 10e,f). By tracing them back to 1800 UTC 10 May ( $6 \mathrm{~h}$ before), the negative correlation centers at low levels are situated to the west (upstream) and near the east coast of Vietnam (indicated by crosses in Figs. 10e,f). Furthermore, the temporal evolution of the correlations between $P_{C}$ and the temperature at low levels from 1800 UTC 10 May to 0000 UTC 11 May are shown in Fig. 11. Comparing Figs. 10e and 10f with Figs. 11b and $11 \mathrm{~d}$, the positive (negative) temperature correlations roughly correspond to the negative (positive) geopotential height correlations. It reveals that the warm low located to the southwest and the cold high to the northeast are conducive to the rainfall in the coastal region, and the sensitive areas are moving eastward with time (Fig. 11).

To illustrate the physical processes discussed above with respect to the correlations, the differences between good members and bad members in geopotential height were plotted with geopotential height averaged from the good members overlaid in Fig. 12. There is a shortwave trough at $500 \mathrm{hPa}$ (around $23^{\circ} \mathrm{N}, 109^{\circ} \mathrm{E}$ ) to the west, upstream of the coastal region for the good members, and 


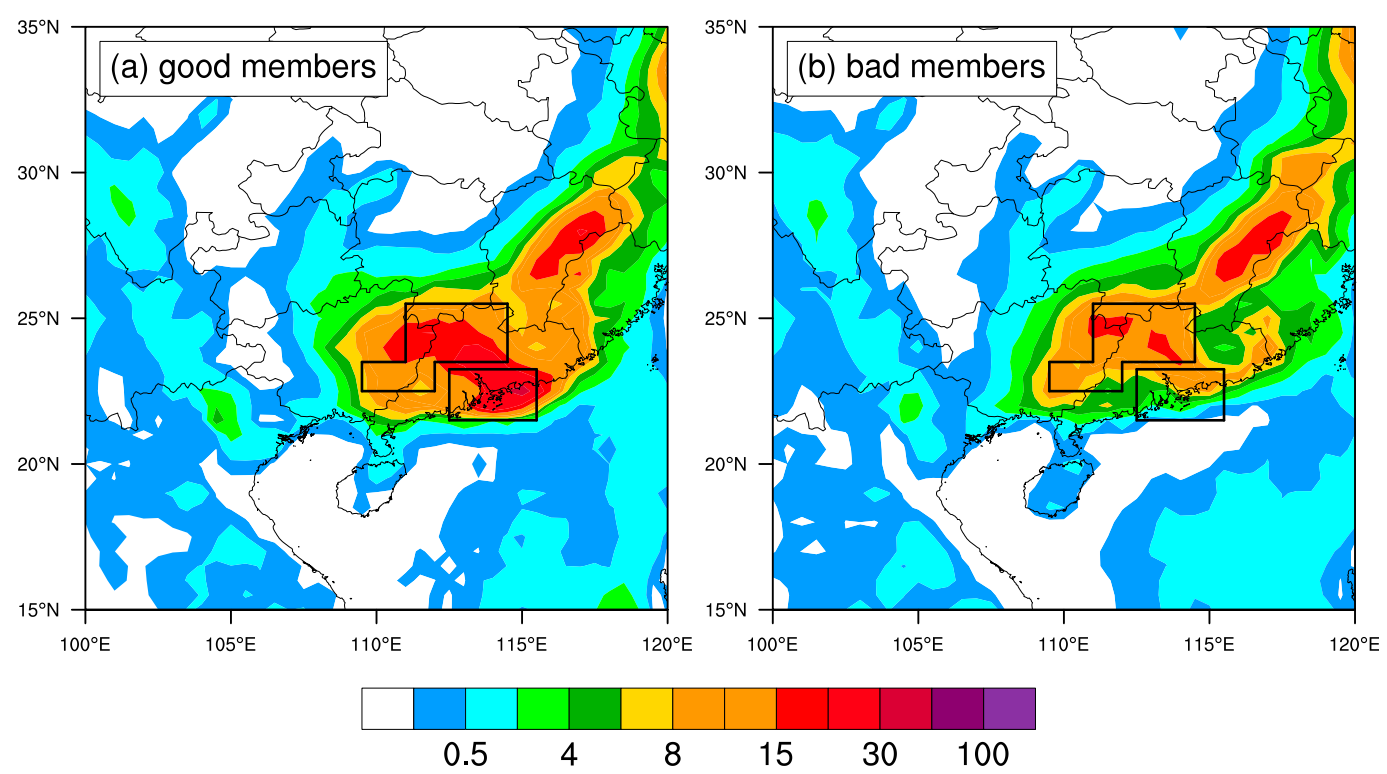

FIG. 8. Distribution of accumulated precipitation ( $\mathrm{mm}$ ) during 0000-0600 UTC 11 May averaged from (a) good members and (b) bad members of the ECMWF ensemble forecasting initialized at 0000 and 1200 UTC 10 May and 0000 UTC 11 May.

it is deeper, compared to the bad members (Fig. 12a). At the low levels $(925-850 \mathrm{hPa})$, a low pressure circulation is situated to the west of the coastal region, which works together with the short-wave trough at upper levels to favor rainfall. In the good members, the pressure at $925-850 \mathrm{hPa}$ tends to be lower to the southeast of the low pressure circulation; thus, the low pressure circulation tends to extend to the southeast and to be stronger in the southeast part. The negative pressure anomaly becomes weaker and also tilted eastward with height (Figs. 12b-d) due to the west-east temperature gradient anomaly (Fig. 11). Such a pressure anomaly enhances the wind speed in the BLJ over the northern region of the SCS by increasing the pressure gradient at low levels. Therefore, the BLJ over the northern region of the SCS is a key factor in the rainfall of the coastal region and might be controlled by the upstream warm low circulation and its boundary processes. In the next section, we will discuss in detail the development of the BLJ that reaches its maximum at 0000 UTC 11 May (Fig. 2e).

\section{d. The development of the BLJ in the ensemble forecasts}

Figures 13a-c show the temporal evolution of wind velocity at $925 \mathrm{hPa}$ averaged from the good members during 1200 UTC 10 May-0000 UTC 11 May. The wind speed over the northern region of the SCS increases with time. In the early morning [0000 UTC (0800 LST)] of 11 May, the wind speed reaches its maximum, and a strong BLJ forms over the northern region of the SCS (around $20.5^{\circ} \mathrm{N}, 113^{\circ} \mathrm{E}$ ). Since the increase in wind speed is significant for the heavy rainfall in the coastal region as indicated above, the formation mechanism of the BLJ is worth studying.

The wind can be decomposed into geostrophic and ageostrophic components. Figures $13 \mathrm{~d}-\mathrm{f}$ and $13 \mathrm{~g}-\mathrm{i}$ present the temporal evolution of the geostrophic and ageostrophic winds at $925 \mathrm{hPa}$ during 1200 UTC 10 May-0000 UTC 11 May, respectively. The geostrophic wind over the northern region of the SCS is approximately southerly and becomes largest at 1200 UTC 10 May (Fig. 13d); it decreases from 1200 to 1800 UTC 10 May (Figs. 13d,e) and increases again from 1800 UTC 10 May to 0000 UTC 11 May (Figs. 13e,f). From a climatological viewpoint, the averaged southerly geostrophic wind in May 1998-2012 reaches its maximum in the late afternoon (1200 UTC; Figs. 14e-h) when the west-east thermal contrast is largest. The geostrophic wind also decreases from 1200 to 1800 UTC, but very slightly increases from 1800 to 0000 UTC (Figs. 14e-h). Therefore, the climatological diurnal cycle of geostrophic wind partly contributes to the evolution of the geostrophic winds in the present case; the significant increase in geostrophic wind over the northern region of the SCS at 0000 UTC 11 May is a response to the enhancement of the low pressure circulation located to the west of the coastal region (Figs. 12d, 10f). In addition, the ageostrophic winds over the northern region of the SCS in the present case are approximately easterly at 1200 UTC 10 May 

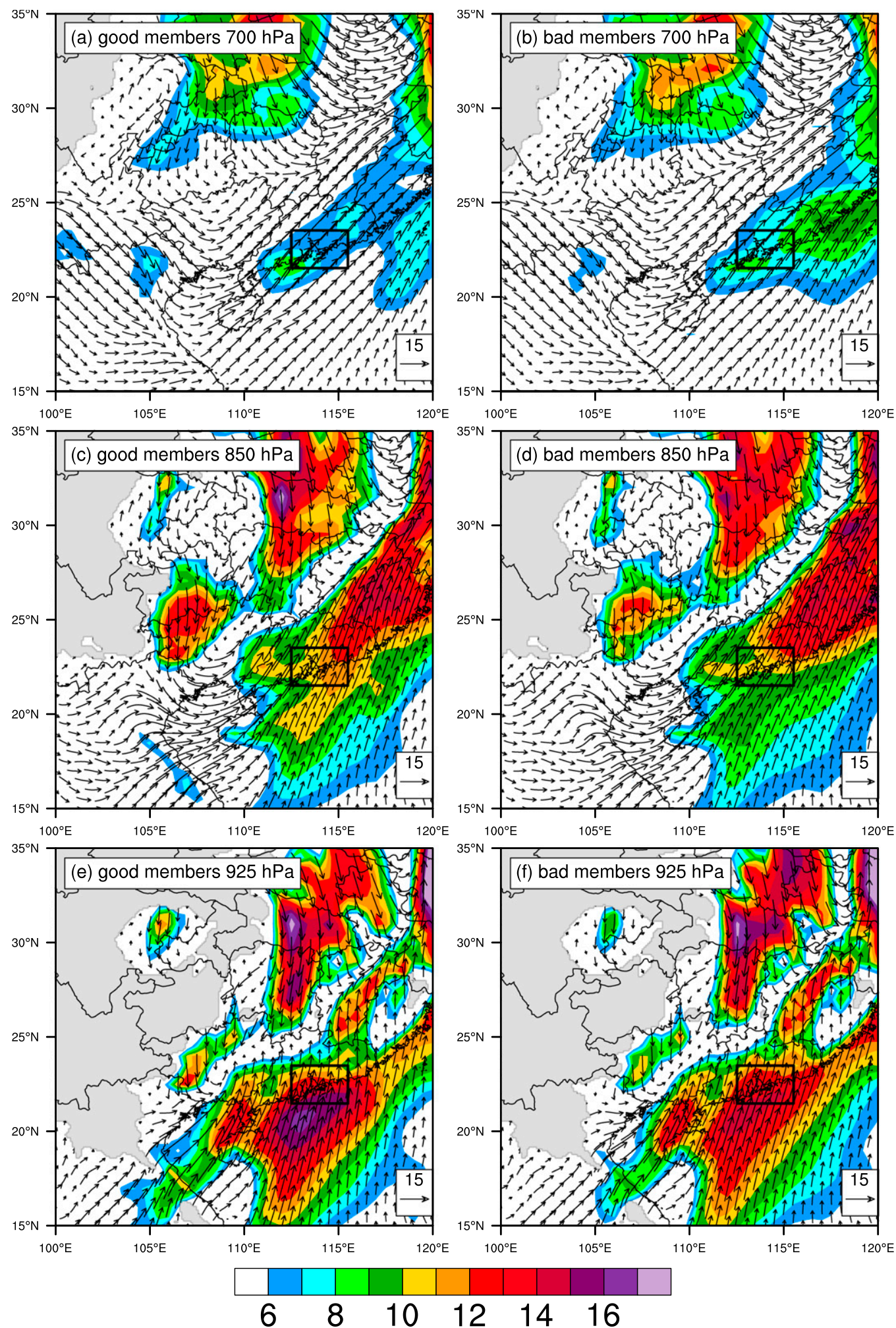

FIG. 9. Wind velocity in the $y$ direction (shading; $\mathrm{m} \mathrm{s}^{-1}$ ) and vectors at (a),(b) 700,(c),(d) 850, and (e),(f) 925-hPa level at 0000 UTC 11 May averaged from (a),(c),(e) good members and (b),(d),(f) bad members of ECMWF ensemble forecasts. 

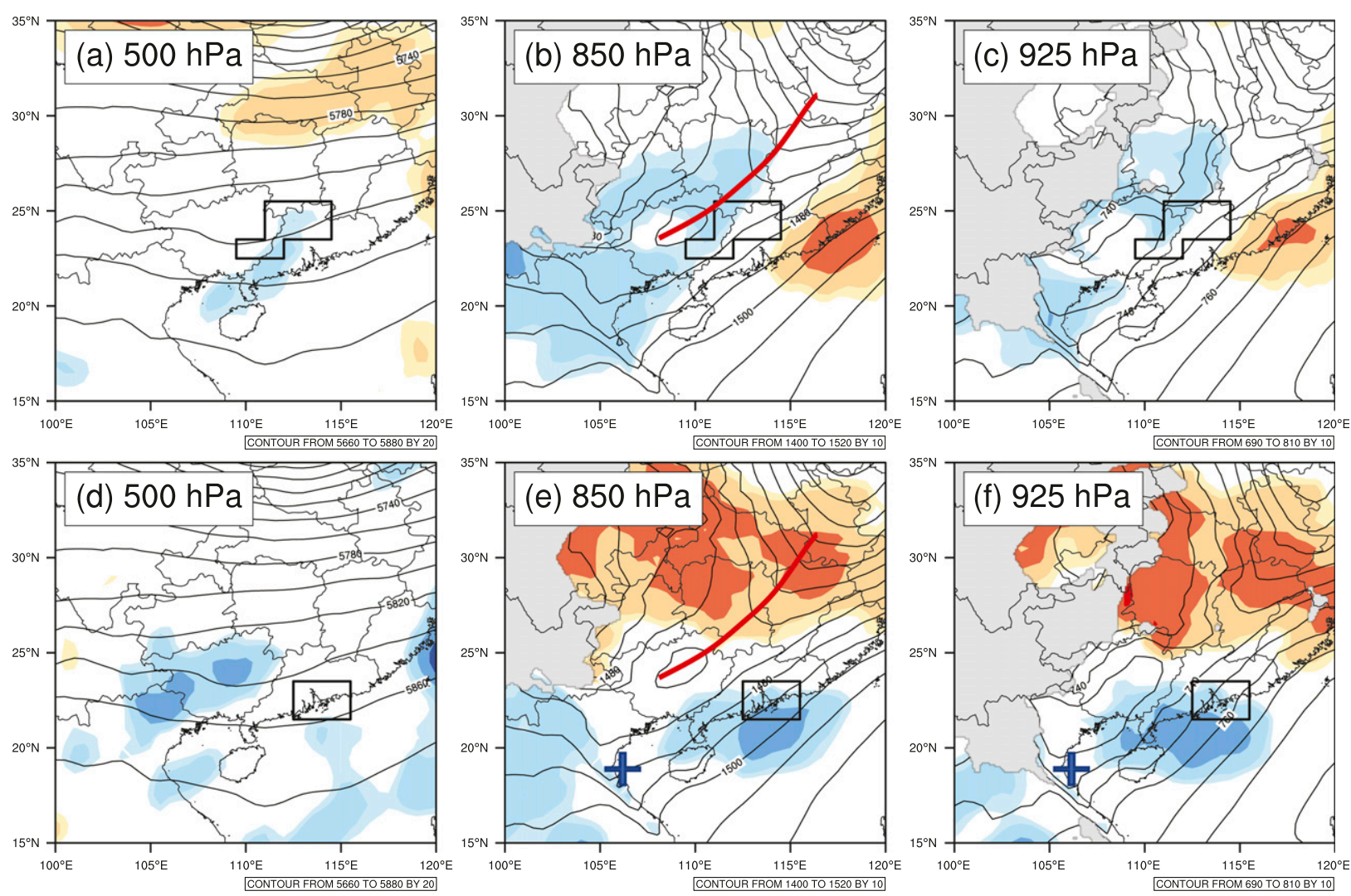

\section{$\begin{array}{llllllllll}-0.5 & -0.4 & -0.3 & -0.2 & -0.16 & 0.16 & 0.2 & 0.3 & 0.4 & 0.5\end{array}$}

FIG. 10. As in Fig. 7, but for geopotential height. The contours show the mean geopotential height. The red lines in (b),(e) indicate the shear line at $850 \mathrm{hPa}$. The crosses in (e),(f) indicate the center of negative correlation of geopotential height at 1800 UTC 10 May (last $6 \mathrm{~h}$ ).

(Fig. 13g) and then veer under the Coriolis force to southerly at 0000 UTC 11 May (Fig. 13i), which also contributes to the maximum winds at 0000 UTC 11 May (Fig. 13c). Such veering of the ageostrophic winds is similar to the inertial oscillation mechanism driven by the thermal contrast between land and ocean, which is documented in the study of BLJ off the southeast coast of China (Du et al. 2015). From the climatological perspective, the ageostrophic wind is northeasterly at 1200 UTC (Fig. 14k) and rotates clockwise to southerly at 1800 UTC (Fig. 14i); it shows a similar, but much weaker, veering signal of the ageostrophic wind in the climatological state.

From the scatterplot of the ensemble members with $P_{C}$ along the ordinate and meridional wind averaged over the BLJ core area along the abscissa (not shown), there is a strong positive linear correlation for the full wind $(r=0.56)$, but a weak linear correlation for the geostrophic wind $(r=0.13)$ and ageostrophic wind $(r=0.23)$. The scatterplot of the ensemble members shows the geostrophic wind and ageostrophic wind are independent (not shown). In the ECMWF ensemble forecasts, the forecast errors of the BLJ are from both geostrophic and ageostrophic winds. The geostrophic and ageostrophic winds are not significantly correlated with $P_{C}$ individually, but their combination is a key factor to the $P_{C}$. In the present case, the errors of geostrophic winds are mainly in the west, upstream of the warm low pressure system, whereas the errors of ageostrophic winds are from the diurnal cycle and boundary processes. The PBL parameterization in the model might lead to uncertainty in the boundary processes.

In summary, the climatological diurnal cycle of winds partly contributes to the evolution of BLJs in the present case. The combination of geostrophic winds and ageostrophic winds in the climatological diurnal cycle makes the BLJ over the northern region of the SCS reach a maximum late at night (1800 UTC; Figs. 14a-d). However, in the present case, the BLJ 

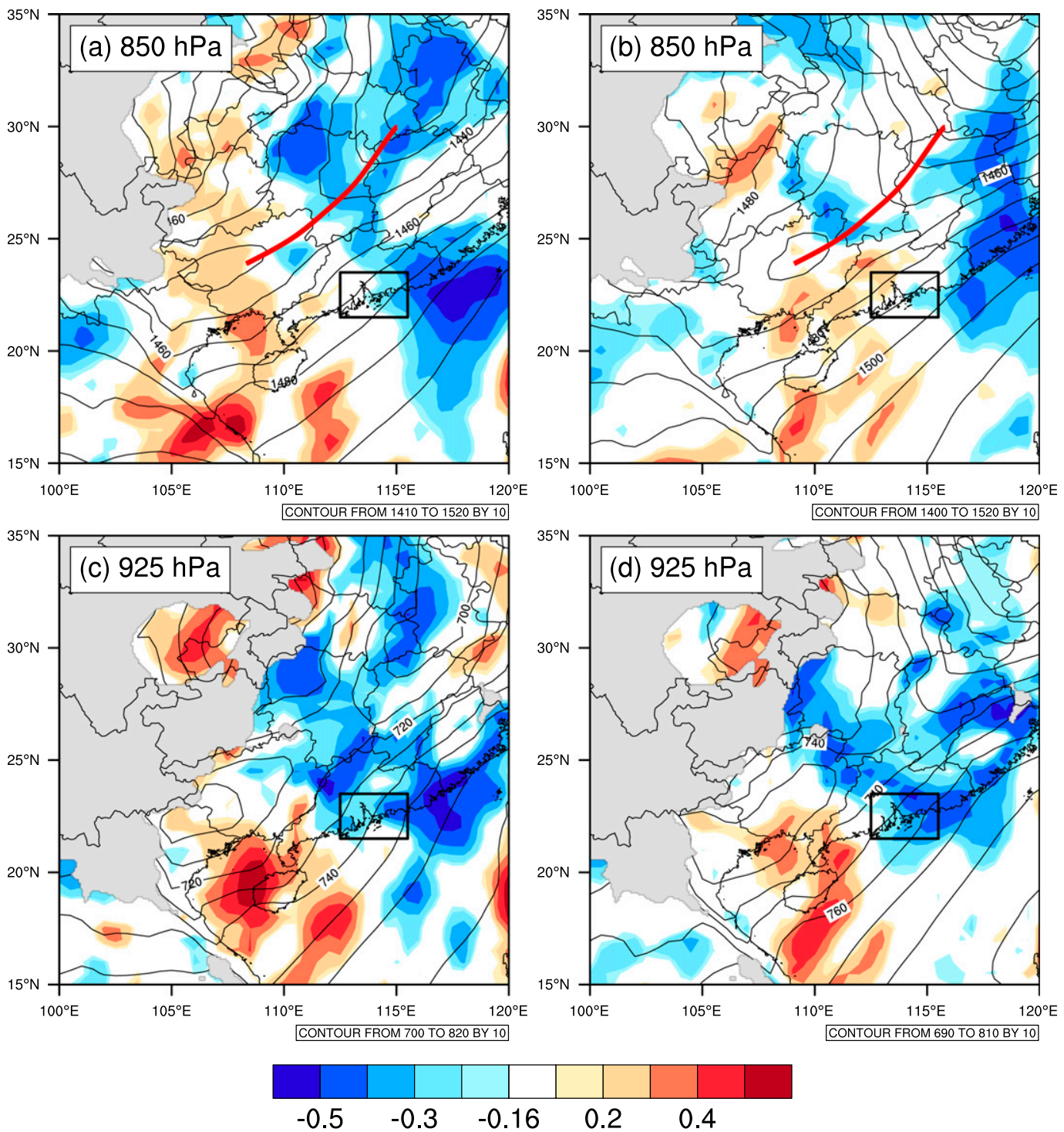

FIG. 11. Mean geopotential height (contour; $\mathrm{m}$ ) and correlation of temperature (shading) at (a),(b) 850 and (c),(d) $925 \mathrm{hPa}$ at (a),(c) 1800 UTC 10 May and (b),(d) 0000 UTC 11 May with area-averaged precipitation during 0000-0600 UTC 11 May over the south region. Red lines indicate shear lines at $850 \mathrm{hPa}$.

peaks in the early morning (0000 UTC 11 May). This morning peak might be related to the upstream low pressure circulation that enhances the geostrophic wind to the southeast of the low pressure circulation at 0000 UTC.

\section{Summary and discussion}

In this study, we use operational global ensemble forecasts from the ECMWF to study the dynamical atmospheric processes influencing the heavy rainfall on 10-11 May 2014. The FNL reanalysis and CMORPH rainfall data indicate that a southwest-northeast-oriented cold front was migrating southward, and there were two types of associated heavy rainfall in Guangdong in the present case: 1) inland frontal heavy rainfall that is related to the cold front and 2) coastal warm-sector heavy rainfall that occurs a few hundred kilometers south, far from the cold front. Analysis of the ensemble mean and spread of ensemble forecasts indicates that the forecast of the coastal warm-sector heavy rainfall is more difficult than that of the inland frontal heavy rainfall. The ensemble mean of ECMWF cannot capture the coastal warm-sector heavy rainfall, though it could reproduce well the inland frontal heavy rainfall. 

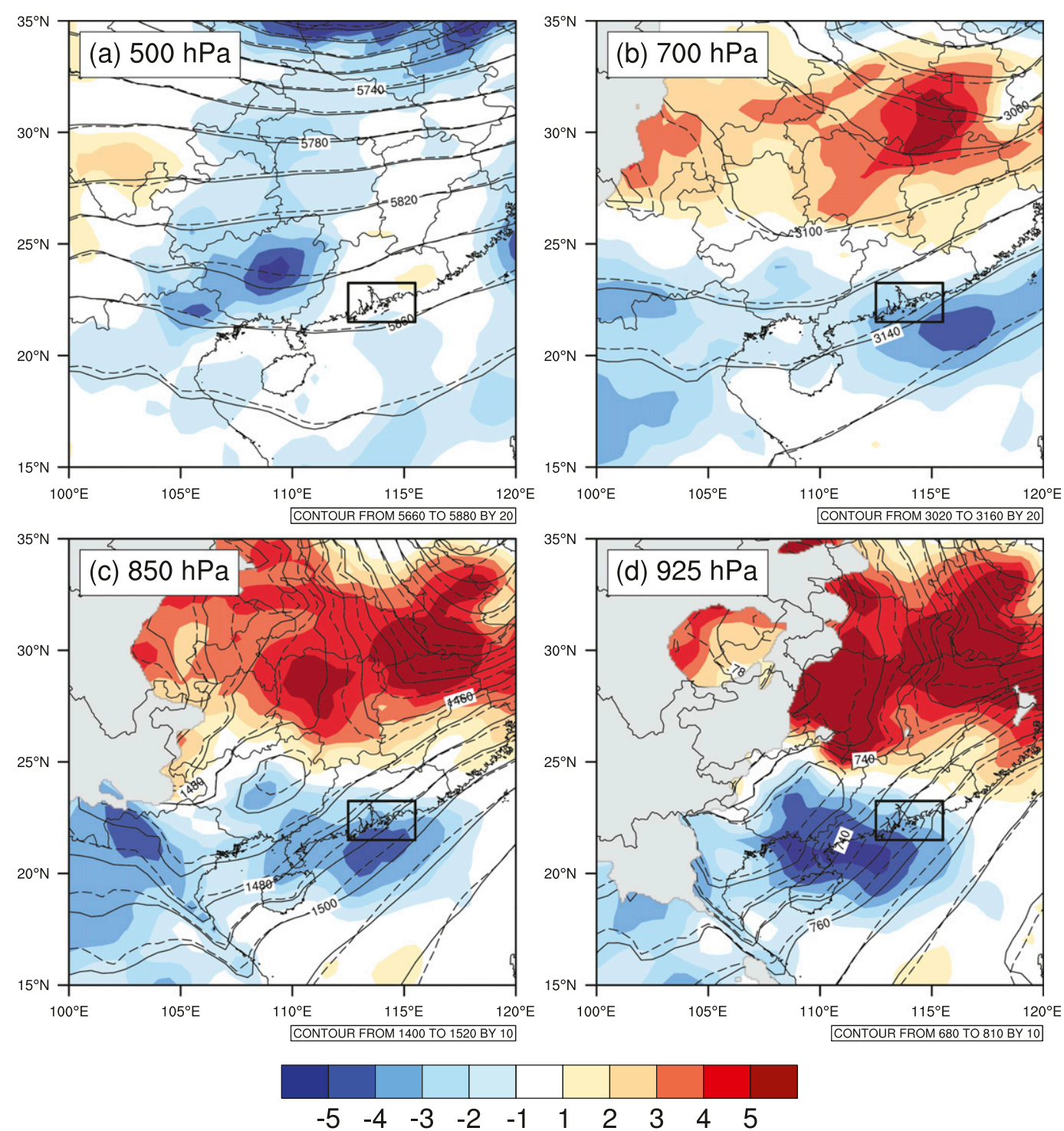

FIG. 12. The difference of height (shading; $\mathrm{m}$ ) averaged between good members and bad members and the height from good cases (contour solid line; m) and bad cases (contour dash line; m) at (a) 500, (b) 700, (c) 850, and (d) $925 \mathrm{hPa}$ from the ECMWF ensemble forecasts at 0000 UTC 11 May.

The ensemble-based analyses suggest that a stronger SLLJ (southwesterly winds at $850-700 \mathrm{hPa}$ ), especially for its meridional wind component, is associated with more precipitation in the frontal zone, whereas a stronger BLJ (southerly winds at $925 \mathrm{hPa}$ ) is related to more rainfall in the coastal warm-sector region. The stronger warm low circulation upstream at low levels cooperating with the deeper short-wave trough at mid-to-high levels leads to more precipitation in the coastal warm-sector region. The comparison of the composites in geopotential height for good members and bad members also supports those results.

In the present case, the BLJ over the northern region of the SCS develops during the evening and reaches a maximum in the early morning (0000 UTC 11 May 2014). Through decomposing the full low-level winds into geostrophic and ageostrophic components, we found that the geostrophic winds are largest in the afternoon because that is the time of the largest thermal contrast between land and ocean, but increase again in the early morning (0000 UTC 11 May) due to the enhancement of the pressure gradient to the southeast of the warm low pressure circulation over southwestern China. For the climatological diurnal cycle of winds, the low-level winds over the northern region of the SCS tend to be stronger late at night. The possible reasons are as follows. Geostrophic winds reach a 

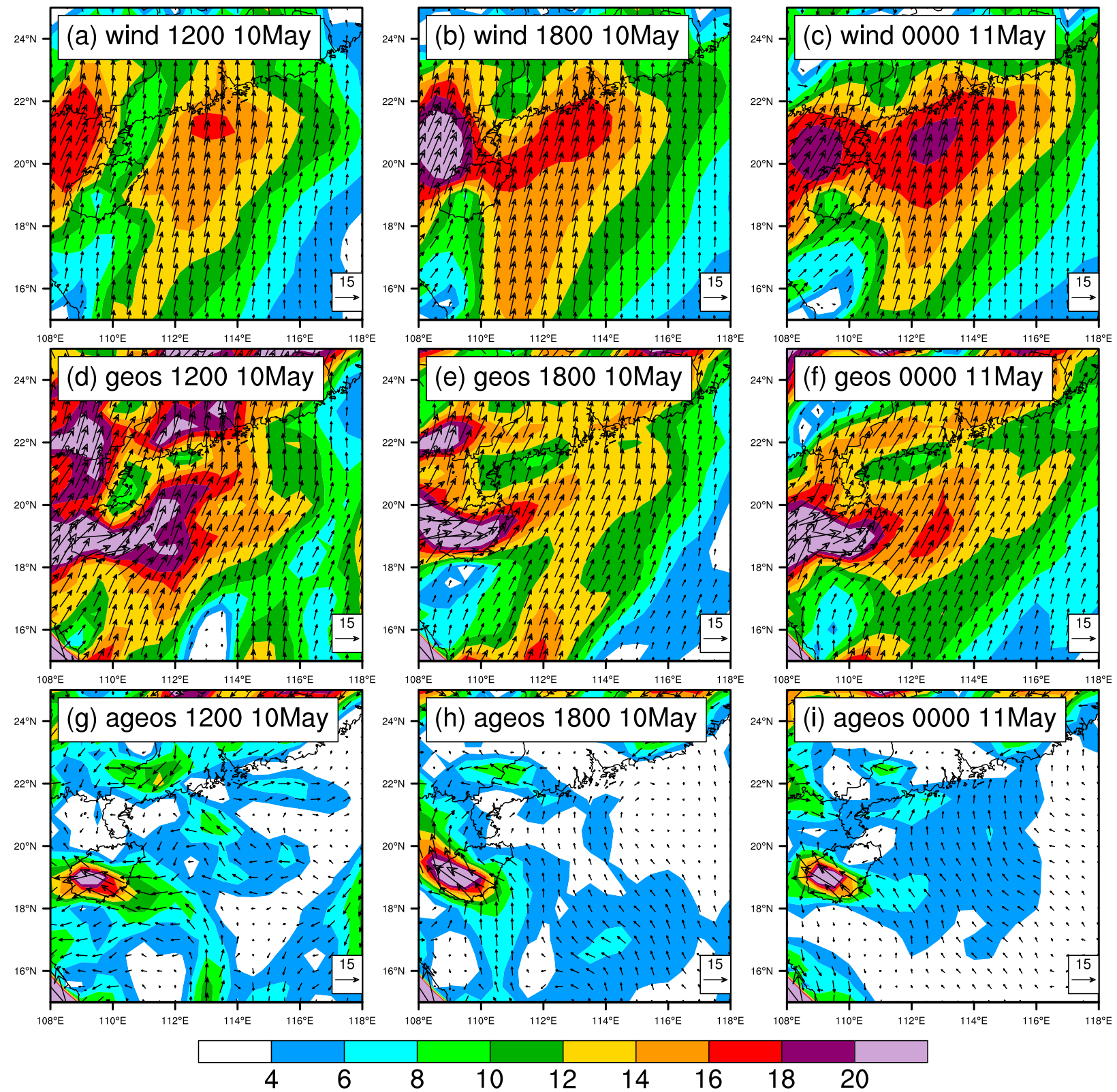

FIG. 13. (a)-(c) Full wind, (d)-(f) geostrophic wind, and (g)-(i) ageostrophic wind (velocity; shading; $\mathrm{m} \mathrm{s}^{-1}$ and vectors) at 925-hPa level averaged from good members of ECMWF ensemble forecasts at (a),(d),(g) 1200 and (b),(e),(h) 1800 UTC 10 May and (c),(f),(i) 0000 UTC 11 May.

maximum in the late afternoon (1200 UTC) when ageostrophic wind is northeasterly. The northeasterly ageostrophic wind veers under the Coriolis force to southerly and combines with the southerly geostrophic wind, resulting in the strongest low-level winds late at night. Thus, the climatological diurnal cycle of winds partly contributes to the evolution of BLJs in the present case.

This study is the first part of a two-part series on heavy rainfall over southern China associated with double low-level jets. We used the ensemble-based analysis method to identify the BLJ and SLLJ as key factors for the warm-sector heavy rainfall and frontal heavy rainfall, respectively. The sensitive area (key factors) to the frontal heavy rainfall is mainly over the land and occurs at relatively high levels, whereas the sensitive area to the warm-sector heavy rainfall is situated over the ocean and occurs at relatively low levels (in the boundary layer). Because of the lack of observations over the ocean and uncertainty of boundary processes 

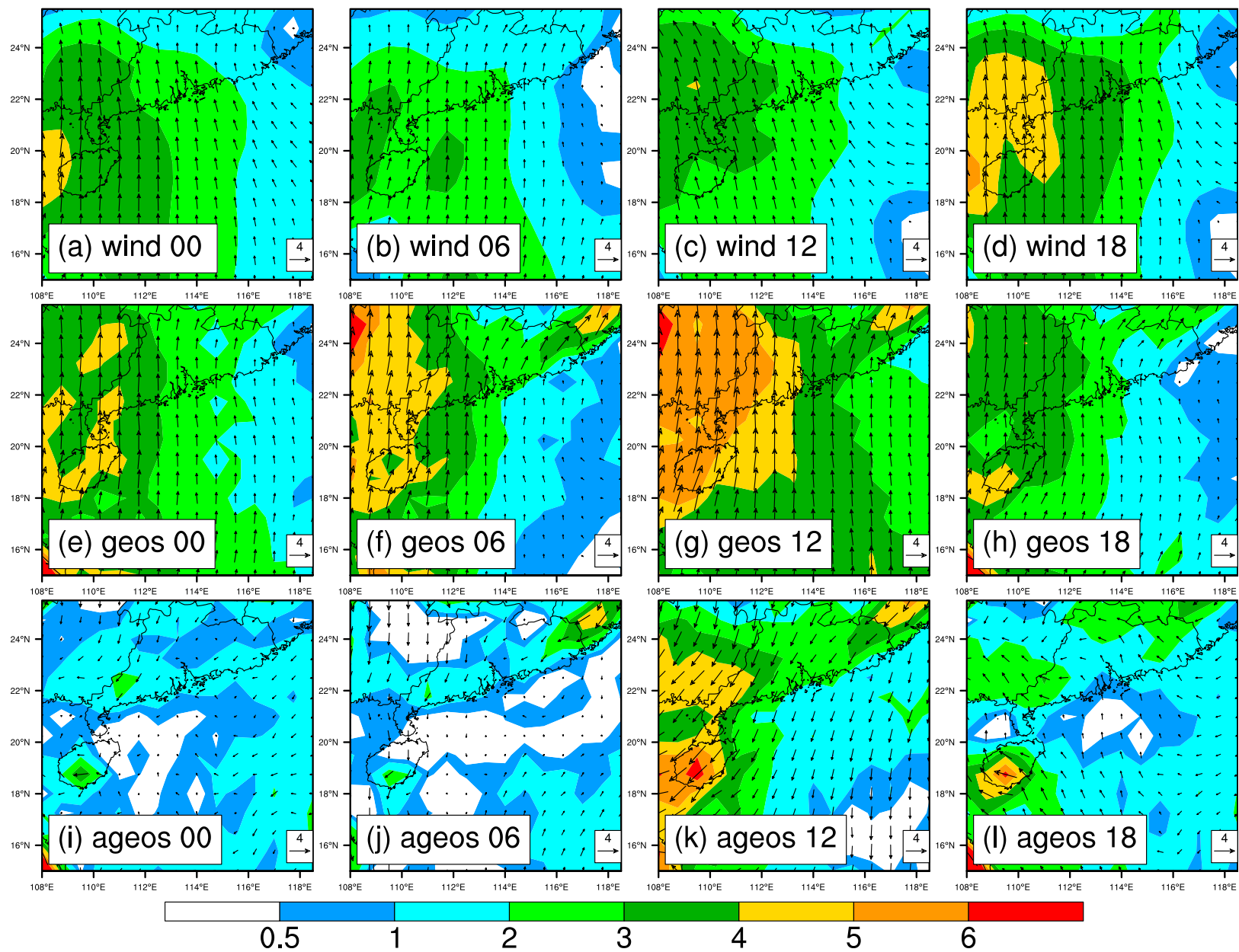

FIG. 14. (a)-(d) Full wind, (e)-(h) geostrophic wind, and (i)-(l) ageostrophic wind (velocity; shading; $\mathrm{m} \mathrm{s}^{-1}$ and vectors) at 925-hPa level from ERA-Interim at (a),(e),(i) 0000, (b),(f),(j) 0600, (c),(g),(k) 1200, and (d),(h),(l) 1800 UTC averaged over May 1998-2012.

in the model, the predictability and forecasting skill of the coastal warm-sector heavy rainfall are relatively low. It might suggest that the improvement of boundary processes in the model and assimilation of observations over the northern region of the SCS would be largely beneficial to the forecasting of the coastal warm-sector heavy rainfall over southern China. In this study, the rainfall in the frontal zone and warm sector shows different dynamical mechanisms and key factors. In the future, similar cases over southern China will be worth studying to confirm the key factors (especially BLJ and SLLJ) found in the present study.

Compared to the frontal rainfall, the forecast of warm-sector heavy rainfall, especially for its convection initiation, remains harder. The mechanisms of convection initiation in the warm sector are still not well understood. In the present study (Part I), LLJs are found as key factors on the synoptic mesoscale to the warm-sector heavy rainfalls over southern China. Nevertheless, how the LLJs affect the convective initiation in the warm sector in detail on mesoscale to microscale is worth further study. Therefore, in Part II, we will investigate the convective initiation mechanisms of the warm-sector heavy rainfall for the same case under the effect of the LLJs through conducting high-resolution numerical simulations.

Acknowledgments. The authors express thanks to the CPC of NOAA for providing CMORPH data and CMA-Guangzhou Joint Research Center for Atmospheric Sciences with support from Guangdong Meteorological Bureau for providing surface data. This study was supported by the National Natural Science Foundation of China (Grants 41875055, 41575068, and 41775094). The authors are thankful to Dr. Richard Rotunno from NCAR for his informal review. 


\section{REFERENCES}

Akiyama, T., 1973: The large-scale aspects of the characteristic features of the Baiu front. Pap. Meteor. Geophys., 24, 157-188, https://doi.org/10.2467/mripapers1950.24.2_157.

Augustine, J. A., and F. Caracena, 1994: Lower-tropospheric precursors to nocturnal MCS development over the central United States. Wea. Forecasting, 9, 116-135, https://doi.org/ 10.1175/1520-0434(1994)009<0116:LTPTNM > 2.0.CO;2.

Blackadar, A. K., 1957: Boundary layer wind maxima and their significance for the growth of nocturnal inversions. Bull. Amer. Meteor. Soc., 38, 283-290, https://doi.org/10.1175/15200477-38.5.283.

Buizza, R., J.-R. Bidlot, N. Wedi, M. Fuentes, M. Hamrud, G. Holt, and F. Vitart, 2007: The new ECMWF VAREPS (Variable Resolution Ensemble Prediction System). Quart. J. Roy. Meteor. Soc., 133, 681-695, https://doi.org/10.1002/qj.75.

Chen, G., R. Lan, W. Zeng, H. Pan, and W. Li, 2018: Diurnal variations of rainfall in surface and satellite observations at the monsoon coast (South China). J. Climate, 31, 1703-1724, https://doi.org/10.1175/JCLI-D-17-0373.1.

Chen, G. T. J., and C. C. Yu, 1988: Study of low-level jet and extremely heavy rainfall over northern Taiwan in the mei-yu season. Mon. Wea. Rev., 116, 884-891, https://doi.org/10.1175/ 1520-0493(1988)116<0884:SOLLJA > 2.0.CO;2.

Chen, Q., 1982: The instability of the gravity-inertia wave and its relation to low-level jet and heavy rainfall. J. Meteor. Soc Japan, 60, 1041-1057, https://doi.org/10.2151/jmsj1965.60.5_1041.

Chen, X., F. Zhang, and K. Zhao, 2017: Influence of monsoonal wind speed and moisture content on intensity and diurnal variations of the mei-yu season coastal rainfall over South China. J. Atmos. Sci., 74, 2835-2856, https://doi.org/10.1175/ JAS-D-17-0081.1.

Chen, Y.-L., X. A. Chen, and Y.-X. Zhang, 1994: A diagnostic study of the low-level jet during TAMEX IOP 5. Mon. Wea. Rev., 122, 2257-2284, https://doi.org/10.1175/1520-0493(1994) $122<2257$ :ADSOTL $>2.0 . \mathrm{CO} ; 2$.

Chou, L. C., C. P. Chang, and R. Williams, 1990: A numerical simulation of the mei-yu front and the associated low level jet. Mon. Wea. Rev., 118, 1408-1428, https://doi.org/10.1175/15200493(1990)118<1408:ANSOTM > 2.0.CO;2.

Ding, Y. H., 1994: Monsoons over China. Kluwer Academic Publishers, 419 pp.

Ding, Z. Y., L. Zhu, Y. Chang, X. Y. Shen, J. H. He, and H. M. Xu, 2008: Research on the causes of double rain belts during a sustained rainstorm (in Chinese). J. Trop. Meteor., 24, 117-126.

Djurić, D., and M. Damiani, 1980: On the formation of the lowlevel jet over Texas. Mon. Wea. Rev., 108, 1854-1865, https:// doi.org/10.1175/1520-0493(1980)108<1854:OTFOTL > 2.0.CO;2.

Du, Y., and R. Rotunno, 2014: A simple analytical model of the nocturnal low-level jet over the Great Plains of the United States. J. Atmos. Sci., 71, 3674-3683, https://doi.org/10.1175/ JAS-D-14-0060.1.

— Q. H. Zhang, Y. Yue, and Y. M. Yang, 2012: Characteristics of low-level jets in Shanghai during the 2008-2009 warm seasons as inferred from wind profiler radar data. J. Meteor. Soc. Japan, 90, 891-903, https://doi.org/10.2151/jmsj.2012-603.

Y. L. Chen, Y. Y. Zhao, and X. Wang, 2014: Numerical simulations of spatial distributions and diurnal variations of low-level jets in China during early summer. J. Climate, 27 5747-5767, https://doi.org/10.1175/JCLI-D-13-00571.1.

_ , Y.-L. Chen, and Q. Zhang, 2015: Numerical simulations of the boundary layer jet off the southeastern coast of China
Mon. Wea. Rev., 143, 1212-1231, https://doi.org/10.1175/MWRD-14-00348.1.

Hakim, G. J., and R. D. Torn, 2008: Ensemble synoptic analysis. Synoptic-Dynamic Meteorology and Weather Analysis and Forecasting: A Tribute to Fred Sanders, Meteor. Monogr., No. 33, Amer. Meteor. Soc., 147-161.

Hering, W. S., and T. R. Borden Jr., 1962: Diurnal variations in the summer wind field over the central United States. J. Atmos. Sci., 19, 81-86, https://doi.org/10.1175/1520-0469(1962)019<0081: DVITSW $>2.0 . \mathrm{CO} ; 2$.

Holton, J. R., 1967: The diurnal boundary layer wind oscillation above sloping terrain. Tellus, 19, 200-205, https://doi.org/10.3402/ tellusa.v19i2.9766.

Huang, L., and Y. Luo, 2017: Evaluation of quantitative precipitation forecasts by TIGGE ensembles for south China during the presummer rainy season. J. Geophys. Res. Atmos., 122, 8494-8516, https://doi.org/10.1002/2017JD026512.

Huang, S. S., and Coauthors, 1986: Heavy Rainfall over Southern China in the Pre-Summer Rainy Season (in Chinese). Guangdong Science and Technology Press, 244 pp.

Jiang, X., N. C. Lau, I. M. Held, and J. J. Ploshay, 2007: Mechanisms of the Great Plains low-level jet as simulated in an AGCM. J. Atmos. Sci., 64, 532-547, https://doi.org/10.1175/JAS3847.1.

Joyce, R. J., J. E. Janowiak, P. A. Arkin, and P. P. Xie, 2004: CMORPH: A method that produces global precipitation estimates from passive microwave and infrared data at high spatial and temporal resolution. J. Hydrometeor., 5, 487-503, https:// doi.org/10.1175/1525-7541(2004)005<0487:CAMTPG >2.0.CO;2.

Luo, Y. 2017: Advances in understanding the early-summer heavy rainfall over South China. The Global Monsoon System, 3rd ed., C.-P. Chang et al., Eds., World Scientific, 215-226, https://doi.org/10.1142/9789813200913_0017.

— , and Coauthors, 2017: The Southern China Monsoon Rainfall Experiment (SCMREX). Bull. Amer. Meteor. Soc., 98, 9991013, https://doi.org/10.1175/BAMS-D-15-00235.1.

Lynch, S. L., and R. S. Schumacher, 2014: Ensemble-based analysis of the May 2010 extreme rainfall in Tennessee and Kentucky. Mon. Wea. Rev., 142, 222-239, https://doi.org/10.1175/MWRD-13-00020.1.

Matsumoto, S., K. Ninomiya, and S. Yoshizumi, 1971: Characteristic features of "Baiu" front associated with heavy rainfall. J. Meteor. Soc. Japan, 49, 267-281, https://doi.org/10.2151/ jmsj1965.49.4_267.

Means, L. L., 1952: On thunderstorm forecasting in the central United States. Mon. Wea. Rev., 80, 165-189, https://doi.org/ 10.1175/1520-0493(1952)080<0165:OTFITC $>2.0 . C O ; 2$.

Newton, C. W., 1967: Severe convective storms. Adv. Geophys., 12, 257-303, https://doi.org/10.1016/S0065-2687(08)60377-5.

Pitchford, K. L., and J. London, 1962: The low-level jet as related to nocturnal thunderstorms over Midwest United States. J. Appl. Meteor., 1, 43-47, https://doi.org/10.1175/1520-0450(1962)001<0043: TLLJAR $>2.0 . \mathrm{CO} ; 2$

Schumacher, R. S., 2011: Ensemble-based analysis of factors leading to the development of a multiday warm-season heavy rain event. Mon. Wea. Rev., 139, 3016-3035, https://doi.org/ 10.1175/MWR-D-10-05022.1.

_ and R. H. Johnson, 2008: Mesoscale processes contributing to extreme rainfall in a midlatitude warm-season flash flood. Mon. Wea. Rev., 136, 3964-3986, https://doi.org/10.1175/ 2008MWR2471.1.

Shapiro, A., E. Fedorovich, and S. Rahimi, 2016: A unified theory for the Great Plains nocturnal low-level jet. J. Atmos. Sci., 73, 3037-3057, https://doi.org/10.1175/JAS-D-15-0307.1. 
Sippel, J. A., and F. Zhang, 2008: A probabilistic analysis of the dynamics and predictability of tropical cyclogenesis. J. Atmos. Sci., 65, 3440-3459, https://doi.org/10.1175/2008JAS2597.1.

, and 2010: Factors affecting the predictability of Hurricane Humberto (2007). J. Atmos. Sci., 67, 1759-1778, https:// doi.org/10.1175/2010JAS3172.1.

Squitieri, B. J., and W. A. Gallus Jr., 2016: WRF forecasts of Great Plains nocturnal low-level jet-driven MCSs. Part I: Correlation between low-level jet forecast accuracy and MCS precipitation forecast skill. Wea. Forecasting, 31, 1301-1323, https://doi.org/ 10.1175/WAF-D-15-0151.1.

Stensrud, D. J., 1996: Importance of low-level jets to climate: A review. J. Climate, 9, 1698-1711, https://doi.org/10.1175/15200442(1996)009<1698:IOLLJT>2.0.CO;2.

Tao, S., and L. Chen, 1987: A review of recent research on the East Asian summer monsoon in China. Monsoon Meteorology, C.-P. Chang and T. N. Krishnamurti, Eds., Oxford University Press, 60-92.

Torn, R. D., 2010: Diagnosis of the downstream ridging associated with extratropical transition using short-term ensemble forecasts. J. Atmos. Sci., 67, 817-833, https://doi.org/10.1175/2009JAS3093.1.

Trier, S. B., D. B. Parsons, and T. J. Matejka, 1990: Observations of a subtropical cold front in a region of complex terrain. Mon. Wea. Rev., 118, 2449-2470, https://doi.org/10.1175/1520-0493(1990) $118<2449$ :OOASCF $>2.0 . \mathrm{CO} ; 2$.

, C. A. Davis, D. A. Ahijevych, M. L. Weisman, and G. H. Bryan, 2006: Mechanisms supporting long-lived episodes of propagating nocturnal convection within a 7-day WRF Model simulation. J. Atmos. Sci., 63, 2437-2461, https://doi.org/10.1175/ JAS3768.1.

Tu, C.-C., Y.-L. Chen, C.-S. Chen, P.-L. Lin, and P.-H. Lin, 2014: A comparison of two heavy rainfall events during the TerrainInfluenced Monsoon Rainfall Experiment (TiMREX) 2008.
Mon. Wea. Rev., 142, 2436-2463, https://doi.org/10.1175/MWRD-13-00293.1.

Uccellini, L. W., 1980: On the role of upper tropospheric jet streaks and leeside cyclogenesis in the development of low-level jet in the Great Plains. Mon. Wea. Rev., 108, 1689-1696, https://doi.org/ 10.1175/1520-0493(1980)108<1689:OTROUT>2.0.CO;2.

— , and D. R. Johnson, 1979: The coupling of upper and lower tropospheric jet streaks and implications for the development of severe convective storms. Mon. Wea. Rev., 107, 682-703, https:// doi.org/10.1175/1520-0493(1979)107<0682:TCOUAL > 2.0.CO;2.

_ , R. A. Petersen, K. Brill, P. Kocin, and J. J. Tuccillo, 1987: Synergistic interactions between an upper-level jet streak and diabatic processes that influence the development of a lowlevel jet and a secondary coastal cyclone. Mon. Wea. Rev., 115, 2227-2261, https://doi.org/10.1175/1520-0493(1987)115<2227: SIBAUL $>2.0 . \mathrm{CO} ; 2$.

Wang, H., Y. Luo, and B. Jou, 2014: Initiation, maintenance, and properties of convection in an extreme rainfall event during SCMREX: Observational analysis. J. Geophys. Res. Atmos., 119, 13 206-13 232, https://doi.org/10.1002/2014JD022339.

Wu, M., and Y. Luo, 2016: Mesoscale observational analysis of lifting mechanism of a warm-sector convective system producing the maximal daily precipitation in China mainland during pre-summer rainy season of 2015. J. Meteor. Res., 30 , 719-736, https://doi.org/10.1007/s13351-016-6089-8.

Zhang, M., and Z. Meng, 2018: Impact of synoptic-scale factors on rainfall forecast in different stages of a persistent heavy rainfall event in South China. J. Geophys. Res. Atmos., 123, 35743593, https://doi.org/10.1002/2017JD028155.

Zhao, S. X., N. F. Bei, and J. H. Sun, 2007: Mesoscale analysis of a heavy rainfall event over Hong Kong during a pre-rainy season in South China. Adv. Atmos. Sci., 24, 555-572, https://doi.org/ 10.1007/s00376-007-0555-2. 